This document was prepared in conjunction with work accomplished under Contract No. DE-AC09-96SR18500 with the U.S. Department of Energy.

This work was prepared under an agreement with and funded by the U.S. Government. Neither the U. S. Government or its employees, nor any of its contractors, subcontractors or their employees, makes any express or implied: 1 . warranty or assumes any legal liability for the accuracy, completeness, or for the use or results of such use of any information, product, or process disclosed; or 2 . representation that such use or results of such use would not infringe privately owned rights; or 3 . endorsement or recommendation of any specifically identified commercial product, process, or service. Any views and opinions of authors expressed in this work do not necessarily state or reflect those of the United States Government, or its contractors, or subcontractors. 


\title{
Hydrogen Embrittlement of Metals: A Primer for the Failure Analyst
}

\author{
M. R. Louthan, Jr. \\ Materials Science and Technology \\ Savannah River National Laboratory \\ Aiken, South Carolina 29808
}

\begin{abstract}
Hydrogen reduces the service life of many metallic components. Such reductions may be manifested as blisters, as a decrease in fatigue resistance, as enhanced creep, as the precipitation of a hydride phase and, most commonly, as unexpected, macroscopically brittle failure. This unexpected, brittle fracture is commonly termed hydrogen embrittlement. Frequently, hydrogen embrittlement occurs after the component has been is service for a period of time and much of the resulting fracture surface is distinctly intergranular. Many failures, particularly of high strength steels, are attributed to hydrogen embrittlement simply because the failure analyst sees intergranular facture in a component that served adequately for a significant period of time. Unfortunately, simply determining that a failure is due to hydrogen embrittlement or some other form of hydrogen induced damage is of no particular help to the customer unless that determination is coupled with recommendations that provide pathways to avoid such damage in future applications. This paper presents qualitative and phenomenological descriptions of the hydrogen damage processes and outlines several metallurgical recommendations that may help reduce the susceptibility of a particular component or system to the various forms of hydrogen damage.
\end{abstract}

\section{Introduction}

The ASM Materials Handbook lists five specific types of hydrogen induced damage to metals and alloys. These types are:

1) hydrogen embrittlement,

2) hydrogen-induced blistering

3) cracking from precipitation of internal hydrogen,

4) hydrogen attack, and

5) cracking from hydride formation.

Except for hydrogen embrittlement, a phase transformation is coupled to each of the listed hydrogen damage process. The forms of hydrogen damage that involve phase transformations are relatively easy to understand in a qualitative fashion and may be minimized by simply paying attention to the damage causing process. Understanding the damage process involved in hydrogen embrittlement is much more elusive and avoiding the damage processes has proven difficult. However, there are several general metallurgical trends that can be helpful in the prevention of hydrogen embrittlement failures. 
This paper provides a qualitative description of the four hydrogen damage processes that involve a phase transformation and a phenomenological description of hydrogen embrittlement.

Additionally, a brief description of hydrogen absorption by, and migration (diffusion) in, metals is included as an aid to understanding some of the hydrogen induced damage processes.

\section{Background}

Hydrogen dissolves in metals as an atom or screened proton rather than as a hydrogen molecule. Therefore, the absorption of hydrogen requires the presence of atomic (nascent) hydrogen on the metal surface. The formation of nascent hydrogen on a metal surface exposed to a gaseous hydrogen environment requires the disassociation of hydrogen molecules as illustrated schematically by Figure 1 . The amount of hydrogen absorbed will depend on the efficiency of the dissociation process which, in turn, depends on the condition of the metal surface. Thin oxide films on metal surfaces significantly reduce the ability of hydrogen to dissociate thus the presence of an oxide has the same impact on hydrogen absorption as lowering the hydrogen pressure would have. A typical 1020 steel component exposed to hydrogen gas at one atmosphere pressure and room temperature will dissolve far less than one ppm of hydrogen. However, when the same component is corroded by acid cleaning, exposure to hydrogen sulfide, or simply by exposure to moisture, the concentration of nascent hydrogen on the surface may become quite high and the hydrogen solubility during the exposure may exceed several ppm. A schematic of the effects of time and temperature on hydrogen absorption by low carbon steels exposed to similar concentrations of various acids is shown in Figure 2. Although no hydrogen concentrations are shown in Figure 2, exposure of steels to acidic solutions generally charges more hydrogen into the metal than exposure to hydrogen gas unless the gas pressure is very high. The tendency for acid exposures to charge hydrogen into a metal is one reason the acid based cleaning solutions should be used with caution (or not at all) if hydrogen is known to affect the performance of the alloy. Numerous steel components have absorbed hydrogen, cracked and failed because of acid cleaning operations.

The absorbed hydrogen in a metal can be present in either of two locations in the microstructure: interstitial sites in the lattice or extraordinary sites typically associated with crystalline defects. Hydrogen absorption causes the iron lattice to expand because the effective size of the nascent hydrogen atom is larger than the size of the interstitial site. This size difference causes hydrogen to prefer extraordinary sites where the "interstitial" site size is expanded and the nascent hydrogen is more readily accommodated. Examples of extraordinary sites include grain boundaries, vacancies, dislocations and any other volume where the interstitial sites are dilated. The impact of extraordinary sites on hydrogen absorption is illustrated by Figure 3. Note that for any given time of exposure to $1 \mathrm{~N}$ sulfuric acid, the amount of hydrogen absorbed increased with increasing cold work. The cold work process increased the dislocation density and vacancy concentrations in the steel and because of the increased concentration of these and other extraordinary sites, the amount of hydrogen absorbed also increased. The concentration of hydrogen at the extraordinary sites in body-centered cubic (ferritic) or body-centered tetragonal (martensitic) steels can greatly exceed the concentration of hydrogen at the normal interstitial sites. Frequently, the hydrogen at extraordinary sites is termed "trapped hydrogen" and the hydrogen at the normal interstitial sites is termed "dissolved or diffusable hydrogen". 
The trapped hydrogen concentration is generally in local equilibrium with the dissolved hydrogen concentration. Local equilibrium can be maintained because hydrogen is mobile in most metals, even at room temperature. Because of this mobility hydrogen atoms are able to jump between normal interstitial sites and extraordinary sites. However, because the extraordinary sites are dilated, the residence time for hydrogen in those sites is much higher than its residence time in normal interstitial sites. This difference in residence time often causes the concentration of trapped hydrogen to exceed the concentration of dissolved hydrogen. The site dependent difference in concentration may be many orders of magnitude for bcc and bct steels at room temperature and only a factor of 2 or so for fcc steels. The mobility of hydrogen increases as temperature increases and differences in residence time at the various sites eventually becomes negligible at high temperatures. Additionally, at temperatures much below room temperature the mobility of hydrogen decreases to the point that relocation cannot occur and local equilibrium cannot be maintained.

This, very simplified description of hydrogen uptake and migration, can be useful in explaining some of the forms of hydrogen damage to metals. Furthermore, this description can be helpful in recognizing practical solutions to hydrogen induced failures in metallic components.

\section{Forms of Hydrogen Damage}

\section{Hydrogen Induced Blistering}

Hydrogen induced blistering occurs during or after hydrogen has been absorbed by the metal. The mobile, nascent hydrogen atoms collect at the extraordinary sites in the metal. Extraordinary sites include the interface between inclusions and the metallic matrix as well as laminations in a wrought structure. Such interfaces are mechanical bonds and provide surfaces inside the metal. As hydrogen collects are this surface the nascent atoms recombine to form a real pressure at the lamination or the inclusion-matrix interface. The magnitude of this pressure will depend on the concentration of absorbed hydrogen in the metal, the trapped-to-dissolved hydrogen ratio and the temperature. If hydrogen was absorbed as the result of exposure to gaseous hydrogen, the interface pressure can never exceed the gaseous hydrogen pressure unless the temperature is higher than the exposure temperature. However, if hydrogen was absorbed because of acid pickling, exposure to hydrogen sulfide, electroplating or cathodic protection the interface pressure may become significant.

The difference between gaseous charging and chemical charging of hydrogen is due to differences in the concentration of nascent hydrogen atoms at the metal surface. During gaseous charging, nascent hydrogen atoms are formed by dissociation of hydrogen molecules while during chemical charging nascent hydrogen is formed as the result of cathodic reactions. The concentration of nascent hydrogen atoms on the surface of a metal during acid pickling may be orders of magnitude higher than the nascent hydrogen atom concentration created by exposure to hydrogen gas even when the gas pressure is exceeds $10,000 \mathrm{psig}$. Therefore, as the nascent hydrogen segregates to an inclusion/matrix interface and recombines to form hydrogen molecules, the real pressure at the interface increases and may reach extremely high levels. Eventually, if there is sufficient hydrogen absorbed in the metal, the pressure will become high enough to plastically deform the surrounding metal. If the deformation is sufficient, a bump or blister will form at the external surface above the 
inclusion or inclusion group. A cross section of a small hydrogen blister in a1020 steel is shown in Figure 4. The phase transformation associated with hydrogen induced blistering is the precipitation of gaseous hydrogen at the inclusion matrix interface. The blister will grow with the accumulation of additional hydrogen as shown in Figure 5 which shows a six inch diameter blister that formed in a $3 / 4$ inch thick steel plate because of hydrogen uptake during the storage of anhydrous HF. Blister formation can occur during the machining of a component because the machining operation removes metal for the surface and thereby lowers the thickness of the metal cap overlying the blister region. This reduction in thickness can reduce the strength of the cap to the point that plastic deformation takes place and a blister is formed.

Blister formation requires that the metal: 1) contain inclusions or other internal surfaces where hydrogen can accumulate, 2) absorb, either prior to or during service, sufficient hydrogen to pressurize the internal surfaces where the accumulation occurred, and 3) remain ductile after hydrogen absorption and in the presence of high pressure hydrogen gas. These three requirements suggest that blister mitigation techniques include: a) the specification of cleanliness in metals and alloys to preclude the presence of large internal surfaces, b) the use of cleaning and processing technologies that minimize hydrogen absorption, c) post process heating to cause hydrogen egress from the metal prior to component manufacture, $d$ ) the use of inhibitors to minimize corrosion of exposed surfaces, and e) the selection of metals and alloys that show little tendency for hydrogen segregation at extraordinary sites (for example austenitic steels rather than ferritic or martensitic steels). However, the economics of operations may require the use of blister susceptible alloys in environments that cause hydrogen absorption.

The development of a hydrogen gas pressure at an internal surface not only leads to plastic deformation but may also alter the deformation and fracture characteristics of the metal. The metal at the tips of blisters, such as those shown in Figures 4 and 5, is highly stressed because of the notches that the blister produces. The stress state at a sharp notch becomes triaxial (increasing triaxiality with increasing blister tip sharpness), dilating the blister tip lattice and creating extraordinary sites for hydrogen accumulation. The ductility of the metal typically decreases as the hydrogen content increases, Figure 6 . The magnitude of the hydrogen induced decrease in ductility typically increases as the strength of the alloy increases (note the strength levels of the steel on the curves shown in Figure 6) thus very little plastic deformation occurs in high strength alloys and a crack, rather than a blister, develops when the hydrogen gas precipitates at internal interfaces.

\section{Cracking from Precipitation of Internal Hydrogen}

Cracks that result from the precipitation of internal hydrogen have been termed fisheyes shatter cracks, and flakes. These forms of hydrogen damage occur in forgings, welds and castings and are attributed to hydrogen absorption in the molten metal. Sources of hydrogen include the formation of nascent hydrogen by the reaction between metal and moisture in the environment. This source of hydrogen and the potential for subsequent hydrogen induced damage to welds is one reason that welding rods are frequently dried by storing and/or heating in a low temperature furnace.

The solubility of hydrogen decreases significantly during solidification and the excess hydrogen precipitates at voids, pores and other internal surfaces. As the pressure in the region of hydrogen precipitation increases the stresses at the tip of the void increase. The presence of high pressure 
hydrogen at the surface of many metals and alloys causes surface defects to extend in a macroscopically brittle fashion, Figure 7 . The void tips cannot blunt in the presence of hydrogen and the lack of blunting causes the tips to remain sharp and extend into the metal. This extension, in ferritic and martensitic steel, generally occurs along prior austenite grain boundaries giving an intergranular appearance to the fracture surface. The hydrogen pressure drops as the crack extends because to void volume increases. Because a high hydrogen pressure is necessary for crack extension, crack growth ceases when the crack reaches a certain size. Fisheyes are produced when this localized hydrogen damage process takes place during a tensile test.

The intergranular fracture process produces a semi-flat surface that is shiny relative to a fracture surface produced by the microviod coalescence process that takes place during tensile overload. Thus when a tensile specimen that contains excess hydrogen precipitated at a void or inclusion is fractured, a macroscopic view of the fracture surface may show a shiny, almost circular "eye" (the intergranular fracture region) contained in a darker matrix (the ductile fracture region), Figure 8. Additionally, the topography of the void or inclusion where hydrogen originally accumulated may provide a pupil for the eye. The fisheye does not generally form until the metal is placed in tension because the hydrogen induced crack growth requires void tip stresses approaching the yield strength of the material. Therefore, components may pass a non-destructive inspection and develop fisheyes after they are placed in service. The fisheye will generally be oriented perpendicular to the maximum tensile stress, thus if the fish eye is formed in a tensile specimen the eye will be perpendicular to the tensile axis.

Fisheyes reduce the cross section of the metal, provide significant stress concentrations and may act as initiation sites for fatigue. Shielding the molten metal from moisture is a key to preventing fisheye formation. This can be accomplished by controlling slag chemistry, vacuum melting and/or the use of dry environments. Even if hydrogen is present in the metal, fisheye formation may be prevented by heating the metal to temperatures slightly above room temperature and giving the hydrogen time to egress from the metal, Figure $8 \mathrm{~b}$. Occasionally, the combination of hydrogen precipitation at voids and interfaces and processing induced stresses (applied or residual) may cause hydrogen induced cracks to grow during fabrication. These cracks are termed, flakes and are most often observed in steel forgings but also occur in steels processed by other techniques.

Flakes develop in much the same way as fisheyes except that the stresses causing the intergranular cracking are developed from forging or rolling processes rather than from tensile testing. The cracks often form during cooling to room temperature because of the residual stresses produced by the plastic deformation associated with processing. The cracks are typically small, associated with flow lines and oriented parallel to the major direction of material flow. The basic difference between flakes and fisheyes is that flakes form during processing while fisheyes form during testing or service. If the combination of stresses, flow lines and hydrogen content cause multidirectional cracking, the hydrogen induced cracks may be termed shatter cracks, rather than flakes or fisheyes. All three types of cracks are formed because a) hydrogen gas has precipitated in micropores or along inclusion metal-interfaces, $b$ ) the presence of hydrogen at the metal surface promotes crack extension by macroscopically brittle processes and c) tensile stresses (applied or residual) are present and high enough to cause crack extension. The term shatter crack probably arose because the multidirectional cracks were first observed in a material that had been forged and 
were thought to have been the result of localized shattering under the blows from the forging hammers.

\section{Hydrogen Attack}

Hydrogen attack occurs when absorbed hydrogen interacts with alloying or impurity elements in the microstructure to form an insoluble, generally gaseous, phase. Two important examples of such attack are hydrogen interactions with copper oxide inclusions in copper alloys to produce steam and hydrogen interactions with carbides in steel to produce methane. These are elevated temperature processes that generally lead to the formation of pressurized, grain boundary cavities.

Copper alloys are susceptible to hydrogen attack because hydrogen can reduce copper oxide, producing copper and water through the reaction

$$
\mathrm{Cu}_{2} \mathrm{O}+2 \mathrm{H}=2 \mathrm{Cu}+\mathrm{H}_{2} \mathrm{O}
$$

When the reaction takes place at temperatures above the critical temperature of water, the copper oxide inclusion is replaced with steam which is virtually insoluble in copper. The resulting steam pocket or bubble exerts a pressure on the surrounding metal producing a bubble or gas pocket. The oxide inclusions that reacted with hydrogen to form steam are generally associated with grain boundaries thus continued bubble development tends to force the grains apart. Bubble coalescence ultimately causes grain boundary fracture. This form of hydrogen embrittlement occurs in copper or copper alloys that contain oxygen and copper oxide inclusions and since oxygen free copper has become easy to produce, steam embrittlement problems are infrequent. However, the potential for steam embrittlement exists whenever copper or other metals and alloys are annealed in hydrogen environments. For example, hydrogen will also reduce silver oxide and steam embrittlement has been observed in oxygen containing silver alloys that were annealed in hydrogen. If the temperature of anneal is below the critical temperature of water, steam is not formed although water containing pores may be produced. Steam embrittlement of copper and copper alloys was a problem when electrolytic tough pitch copper dominated the market but the switch to oxygen free coppers has virtually eliminated the problem. However, hydrogen attack of steels remains a significant industrial problem, especially in the petrochemical industry.

The exposure of steel components to high temperatures and high hydrogen pressures can alter the microstructure, degrade the strength and ultimately cause fracture. The degradation in mechanical properties only occurs after an incubation period during which little or no change in properties are measured. However, the process of decarburization begins almost as soon as the steel is exposed to the hydrogen/temperature combination. Decarburization initiates as surface reactions between hydrogen in the environment and carbon in the steel. The reaction product is methane which is released to the surrounding environment. This reaction decarburizes the near surface region and, if continued, lowers the carbon content in the near surface region to the point that carbides, for example the $\mathrm{Fe}_{3} \mathrm{C}$ in pearlite, begin to dissociate. The decarburization and carbide removal processes lower the strength of the steel.

The exposure also causes hydrogen to be absorbed by the steel. The absorbed hydrogen is very mobile and begins to accumulate at pores and micropores associated with the grain boundary 
inclusions or other microstructural defects. Inside the pores the absorbed nascent hydrogen recombines to form hydrogen molecules which react with carbon to form methane by the same reaction that initially caused surface decarburization. This reaction,

$$
2 \mathrm{H}_{2}+\mathrm{C}=\mathrm{CH}_{4}
$$

coupled with the cementite decomposition reaction,

$$
\mathrm{Fe}_{3} \mathrm{C}=3 \mathrm{Fe}+\mathrm{C}
$$

thermodynamically favors methane formation when the temperature exceeds approximately $200 \mathrm{C}$. Furthermore methane may be formed by direct interaction between the diffusing hydrogen and carbide particles. The methane that forms is insoluble in the steel and thus remains in the micropore or defect caused by removal of the carbide. As the amount of methane in the pore increases the pressure inside the pore increases until either equilibrium is reached or the pressure becomes sufficient to expand the pore. The methane pressure in equilibrium with $\mathrm{M}_{3} \mathrm{C}$ carbides in a commercial quenched and tempered 2.25Cr-1Mo steel at 500 and $600 \mathrm{C}$ is shown in Figure 9 as a function of the hydrogen partial pressure. The equilibrium methane pressure depends on the stability of the carbides, thus minor alloy additions of strong carbide formers ( $\mathrm{V}, \mathrm{Ti}, \mathrm{Nb}$, etc.) will minimize the methane pressure that develops within the pore and promote a resistance to hydrogen attack.

The methane pressure within a pore may become sufficient to drive pore growth if the equilibrium pressure is high. Additionally, even if the equilibrium pressure is low, the applied stresses acting on the steel may couple with the internal gas pressure to cause creep like growth of the pores. Grain boundary diffusion, surface diffusion and dislocation motion all play a role in the pore growth process. Continued pore growth leads to the coalescence of the microcavaties, microcrack formation and linkup of the microcracks to form an intergranular crack, Figure 10. The intergranular cracking process reduces the cross section supporting the load and ultimately leads to fracture of the steel. Factors affecting the hydrogen attack processes include temperature, partial pressure of hydrogen, time, steel chemistry, initial microstructure of the steel and the purity of the hydrogen environment. The example of hydrogen attack shown in Figure 10 is interesting because of the complicated nature of the process. Localized corrosion occurred under a deposit that had built up on a boiler tube. The hydrogen generated by the corrosion diffused into the steel causing decarburization, intergranular cracking and ultimately failure. This scenario illustrates the potential importance of hydrogen attack, even in systems where such attack is not typically considered.

Qualitatively, hydrogen attack is relatively well understood and although successful, theoretically based models of the process have been elusive, an empirical model of the process has been very successful. The Nelson Curves are published relatively regularly by the American Petroleum Institute (API). These curves delineate the safe operating ranges, in terms of temperature and hydrogen partial pressure, for various alloys used in the petrochemical industry. The curves are primarily based on practical experience and engineering judgment. Analysis of the curves demonstrates that the maximum hydrogen pressure specific steels can withstand without hydrogen attack decreases as the temperature increases and that hydrogen attack does not occur below a certain, alloy dependent temperature, Figure 11a. Time of exposure is also important as illustrated 
in Figure 11b, and a true Nelson Curve is only developed after prolonged exposures to the hydrogenous environments. Although the Nelson curves only provide general, empirical guidelines for materials selection for application in high temperature hydrogen service, it is unlikely that anyone with experience in the petrochemical industry would willingly disregard a Nelson Curve and use steels under conditions where hydrogen attack is considered probable. Industrial operations such as welding and cold work can have deleterious effects on the resistance to hydrogen attack and alter the Nelson Curve, as can the presence of moisture in the hydrogen and/or prior exposure to a high temperature hydrogen environment.

The adverse effects of exposing materials to hydrogen at elevated temperatures are not limited to metals. Mullite, for example, looses strength when exposed to hydrogen at 1050 and $1250 \mathrm{C}$. Stoichiometric mullite is $3 \mathrm{Al}_{2} \mathrm{O}_{3}-2 \mathrm{SiO}_{2}$ and its high temperature properties provide the potential for use in a verity of applications. However, exposure to hydrogen gas removes silicon from the material (Figure 12) and reduces the strength. Silicon is removed by the reaction

$$
\mathrm{SiO}_{2}(\text { solid })+\mathrm{H}_{2}(\text { gas })=\mathrm{SiO}(\text { gas })+\mathrm{H}_{2} \mathrm{O} \text { (gas) }
$$

Hydrogen is a very effective reducing agent as illustrated by the experience with mullite. Therefore, whenever a material is exposed to high temperature hydrogen environments, regardless of the hydrogen pressure, some consideration should be given to the potential for hydrogen interaction with components of, or microstructural elements in, the material.

\section{Cracking from Hydride Formation}

Zirconium, titanium, tantalum and other transition, rare earth and alkaline rare earth metals form hydrides when the hydrogen concentration exceeds a certain level. A hydrogen/metal phase diagram representative of these metals and their alloys is illustrated in Figure 13a. The maximum solubility of hydrogen in many hydride forming metals and alloys is not great. For example, titanium dissolves 0.2 weight percent hydrogen when exposed to one atmosphere hydrogen gas at $300 \mathrm{C}$ and zirconium only dissolves 0.07 weight percent hydrogen if exposed to one atmosphere hydrogen at $550 \mathrm{C}$. However, even this low concentration exceeds the hydrogen solubility in Fe, $\mathrm{Cu}, \mathrm{Al}$ and other non-hydride forming metals. Aluminum will only dissolve about $10^{-6}$ weight percent hydrogen when exposed to one atmosphere hydrogen at $660 \mathrm{C}$ while Fe will dissolve 0.0003 weight percent hydrogen at $912 \mathrm{C}$ and copper will dissolve 0.003 weight percent hydrogen at $1075 \mathrm{C}$. In addition to generally having much lower hydrogen solubilities, the non-hydride forming metals have fundamentally different phase diagrams as illustrated by Figure 13b. This fundamental difference in the phase diagrams results in a fundamental difference in the hydrogen damage processes. When the hydrogen content of aluminum or steel exceeds the solubility limit hydrogen gas bubbles should precipitate in the metal lattice, leading to hydrogen induced blistering or cracking. In contrast, when the hydrogen content of zirconium, titanium, uranium and other hydride forming metals exceeds the solubility limit, metal hydrides precipitate. The hydrides are typically low density, brittle compounds whose presence degrades the ductility of the alloy. Additionally, applied and/or residual stresses may interact with the stresses associated with the volume expansion of the low density hydride phase and effect the orientation and distribution of the hydride precipitates. 
The hydride induced degradation in ductility can manifest itself in several ways. Very small hydrides may act as microvoid initiation sites and decrease the ductility simply by increasing the ease of microvoid coalescence. The fracture of larger hydrides (or hydride/metal interfaces) produces a crack in the matrix. The stress concentration at this crack tip localizes subsequent plastic strain and, depending on the hydride quantity, orientation and distribution may significantly reduce the ductility of the alloy. Finally, the hydrogen containing material may be placed in service and the stress (either applied or residual) and thermal gradients associated with the service may cause hydrogen redistribution. Hydrogen will accumulate at the regions of high dilatational stresses and eventually precipitate as a hydride. The brittle hydride (or hydride metal interface) will fracture, relieving the stresses that acted on the hydride. The stress will now be concentrated at the new crack tip and hydrogen will begin to migrate to the newly stressed region. The hydrogen accumulation- hydride precipitation-fracture process will then be repeated at the new crack tip. This sequence of events will continue to occur until the crack reaches a critical size and the component fractures or until the stresses are relieved. This form of delayed failure hydrogen embrittlement is frequently termed sustained load crack growth and has caused cracking in alpha or near alpha phase zirconium and titanium alloy welds. These weld cracks can be driven by the welding residual stresses and may not develop until weeks after the weld has been completed. Such post weld cracking can generally be avoided by using dry welding rods and inert gas shielding to prevent hydrogen uptake during welding.

The orientation of the hydride precipitate at a crack tip is seldom random. Because of the large volume expansion that accompanies hydride nucleation and growth, hydride platelets tend to precipitate perpendicular to tensile stresses and parallel to compressive stresses as shown in Figure 14. This tendency is termed stress orientation and hydride precipitation during stress orientation may be either intergranular or across the grains with the platelets lying along any of the hydride habit planes. Additionally, in cold formed material the platelets will tend to be oriented parallel to the forming direction as shown in Figure 15. The tendency for hydrides to be oriented parallel to the direction of cold forming is termed strain orientation. The combined effects of stress and strain orientation causes the orientation of the hydride platelets in any particular component to depend on the fabrication processes used to produce the component and the applied and residual stresses acting on the component.

Hydrogen in most hydride forming metals and alloys is mobile at room temperature, thus hydride reorientation may occur during service. The ease of hydride re-orientation is apparent in Figure 16 which shows a gauge mark on a Zircaloy-2 tensile specimen. The gauge mark was placed on the specimen at room temperature and the as-marked specimen was sectioned for metallography. The hydrides beneath the mark have a distinctly different orientation than the randomly oriented hydrides remote from the mark. The brittleness of the hydride phase makes it unlikely that the hydride rotated during the marking process, thus suggesting that the reorientation involved the dissolution and reprecipitation of the zirconium hydrides.

The influence of hydride precipitation on the mechanical properties depends on the hydride orientation and the distribution of the hydrides within the component. Unfortunately, when stresses are acting on the component, hydrides tend precipitate so that the potential for degrading the properties is maximized. Individual hydride platelets will be oriented perpendicular to any tensile stresses acting on the component and the hydrides will tend to cluster so that rows or columns of 
platelets are formed. Such columns are apparent in Figure 14 and, because of limited ductility, the hydrides and hydride-metal interfaces provide an easy path for crack propagation along the hydride column and across the material.

Stress induced reorientation of hydrides is a continuing concern in the nuclear power industry where zirconium alloys are used to clad nuclear fuels. Service conditions include exposure to, and corrosion in, hydrogenous environments (water). The corrosion process causes hydrogen uptake that can lead to the precipitation of additional hydrides. The newly formed hydrides will be susceptible to stress or strain orientation. The combination of hydrogen uptake during operation and storage, thermal gradients across the cladding and hoop stresses acting on the cladding may cause columns of radial hydrides to precipitate in the cladding and ultimately lead to cladding degradation and exposure of the underlying nuclear fuel.

In addition to the hydride induced degradation observed in uranium, alpha titanium and alpha zirconium alloys, hydrogen degrades beta titanium, vanadium, tantalum and niobium alloys by raising the ductile-to-brittle transition temperature. An example of this transition in Timet $21 \mathrm{~S}$ titanium (Ti-15Mo-3NB-3Al-0.2Si) is shown in Figure 17 and the influence of hydrogen on the transition temperature is shown in Figure 18. The hydrogen concentration in the Timet $21 \mathrm{~S}$ was less than the solubility of hydrogen in beta titanium and no hydrides were detected by x-ray diffraction, thus the hydrogen induced effects are not attributed to hydrides. The effects appear to be due to the combined effects of absorbed hydrogen on the yield and fracture strengths of the material. Hydrogen absorption raises the yield strength and lowers the fracture strength of the material. In this respect, the hydrogen induced damage in beta titanium is similar to the hydrogen damage processes involved in hydrogen embrittlement.

\section{Hydrogen Embrittlement}

The four forms of hydrogen damage discussed previously (blistering, cracking from precipitation of internal hydrogen, hydrogen attack and cracking from hydride formation) can be qualitatively understood by considering the influence of a phase transformation (precipitation of a hydrogen gas bubble, the production of an insoluble gaseous product or the precipitation of a hydride) on the mechanical properties. An understanding of the fifth form of hydrogen damage (hydrogen embrittlement) is much more elusive even though the first published papers on the subject were published over a century ago. Early work demonstrated that the susceptibility of mild steels to hydrogen embrittlement during a tensile test is dependent on the test temperature and strain rate, Figure 19. Other work showed that hydrogen embrittlement could occur when the applied stress level was below the yield strength of the material. In this case the hydrogen embrittlement process is similar to the delayed failure hydride embrittlement in titanium and zirconium welds, except that no hydride phase is formed. In fact, the term delayed failure originated from descriptions of hydrogen embrittlement in steels. Qualitatively delayed failure hydrogen embrittlement involves the following generalized processes:

1) Hydrogen is introduced into the component during manufacture (or service).

2) The absorbed hydrogen atom is too large to fit comfortably in the interstitial sites in the metal lattice and because of its mobility will migrate to extraordinary sites where the lattice is dilated. 
3) The extraordinary sites in an unstressed component are randomly distributed throughout the material and consist primarily of inclusions, precipitates, dislocation tangles, grain boundaries and other such microstructural features. The hydrogen is therefore distributed in a macroscopically random fashion and the local accumulations do not produce local fractures. This lack of hydrogen induced damage will persist until the component is placed in service.

4) The service induced loads will result in concentrated stresses which produce localized, macroscopic regions of lattice dilation. For example, the region immediately below a thread root of a loaded bolt. Hydrogen will then migrate to this region of lattice dilation. When the hydrogen concentration in that localized region reaches a critical level, a crack will nucleate and propagate through the region that has the high hydrogen concentration. (The time required for this event to occur will depend on the metallurgical condition of the material, temperature of exposure, hydrogen content in the material and the magnitude of the stress concentration. The mechanism by which the hydrogen induced cracks nucleate and propagate remains a subject for scientific debate but this paper will assume that hydrogen lowers the strength of the various microscopic interfaces in the material and facilitates dislocation nucleation at the crack tip.)

5) The crack nucleation and/or extension process relieves the stresses and associated lattice dilation in the cracked region and moves the region of high stress and lattice dilation to a zone immediately below the new crack tip.

6) Hydrogen will relocate to the newly dilated zone and the crack nucleation/propagation process will repeat until either the crack reaches a critical size and the component fractures or the stresses acting on the component have decreased to the point that a critical hydrogen concentration cannot be reached in the region of lattice dilation.

Some of the sources of hydrogen and microstructural variables involved in this highly simplified, six step scenario are illustrated in Figure 20. Factors that are important to the analysis and prevention of failures include the role of lattice dilation in causing hydrogen relocation, necessity for hydrogen diffusion during the hydrogen relocation process and the existence of a critical hydrogen concentration for embrittlement.

Hydrogen lowers the strength of various interfaces in metals and alloys. This effect is evident from observations of hydrogen assisted cracking along grain boundaries, twin boundaries, martensite lathes, prior austenite grain boundaries, slip bands, particle (precipitate)-matrix boundaries and other microstructural interfaces, as indicated in Figure 20. Interfacial, hydrogen induced cracks have been observed in high and low strength steels, austenitic stainless steels, nickel and nickel based alloys, high strength aluminum alloys and in several hydride forming alloys under conditions where no hydrides were anticipated. Many of these same interfaces have, through autoradiography (Figure 21 for example), been shown to be sites where hydrogen accumulates, even in non-stressed materials.

The extent of interfacial fracture in any particular sample or component can be determined by fractography. The tendency to assume that hydrogen embrittlement can readily be identified through the observation of intergranular fracture should be avoided, even though intergranular fracture is a common feature of hydrogen assisted cracking in high strength steels. The effects of hydrogen on fracture processes may be as subtle as a decrease in microvoid size and include the 
development of a facetted fracture surface topography because of slip band or twin boundary parting. Hydrogen induced cleavage of the metal lattice has also been observed, as has hydrogen induced intergranular cracking. The appearance of intergranular cracking in a normally ductile material is often considered to be an obvious indicator of hydrogen embrittlement but is neither necessary nor sufficient to confirm that a component failed because of hydrogen embrittlement. The difficulty of simply using fractography to identify the cause of a failure is illustrated in Figure 22 which shows hydrogen assisted cracking having occurred primarily by ductile fracture processes and intergranular fracture of the same material having occurred because of temper embrittlement. A unique fracture mode characteristic of a hydrogen embrittlement does not exist. The characteristics of hydrogen assisted fracture are dependent on the metallurgical condition of the material, the hydrogen content and the exposure environment, temperature and loading conditions, including strain rate.

The strain rate dependence of body centered cubic mild steels to hydrogen embrittlement is shown in Figure 19. Similar strain rate dependencies have been found for other metals and alloys and a key point of these observations is that hydrogen embrittlement increases as the strain rate decreases. This point, when extrapolated to the extreme, suggests that the maximum susceptibility to embrittlement would be produced by static loads. This is the case to a certain extent because some alloys are susceptible to delayed failure hydrogen embrittlement. These alloys, when loaded to around $80 \%$ of their yield strength and held under load for a period of time, will fracture with essentially no macroscopic plastic strain. The susceptibility delayed failure hydrogen embrittlement is a function of the metallurgical condition of the material. The time required for delayed failure also depends on hydrogen content, stress level and the degree of stress concentration. A schematic illustration of stress-time dependence of delayed failure is shown in Figure 23 and the effect of stress concentrations in Figure 24. Figures 23 and 24 are based on studies with notched tensile specimens. More modern treatments of delayed failure processes use fracture mechanics techniques to determine the influence of applied stress intensity on crack growth rates (Figure 25). There are three critical "levels" of applied stress intensity: Stage I represents the minimum stress intensity necessary to cause hydrogen induced crack growth, Stage II represents a region where the sub-critical crack velocities are relatively independent of applied stress intensity and Stage III represents unstable crack growth and approaches the critical stress intensity necessary to fracture the material in the absence of hydrogen.

Stage I and II cracking are significant because they characterize crack growth over a large range of stress intensities that are relevant to practical design considerations. Extrapolation of Stage I (dashed line in Figure 25) provides an estimate of the threshold stress intensity necessary to cause hydrogen induced cracking while Stage II shows the potential rates at which hydrogen induced cracks might grow. Analysis of Stage II crack velocities and hydrogen diffusivities has shown that the fastest rates of Stage II intergranular cracking are directly proportional to hydrogen diffusivity for a wide range of high strength steels, nickel alloys and aluminum alloys, Figure 26. This proportionality is consistent with the hydrogen embrittlement model that assumes a critical, localized region of very high hydrogen concentration is a precursor to hydrogen embrittlement. The size of this localized region remains the subject of debate and there is evidence that whatever the size may be $(10 \mathrm{~nm}$ or $10 \mu \mathrm{m})$ in hydrogen charged material, exposure of the material to an external hydrogen pressure reduces that size. This observation is consistent with a model for hydrogen induced crack propagation where hydrogen promotes interfacial fracture and facilitates 
dislocation nucleation at a crack tip. However, it is important for the failure analyst to recognize that it is unlikely that any single mechanism for hydrogen embrittlement is valid for all hydrogen induced embrittlement processes.

Hydrogen induced sub-critical crack growth in statically loaded materials exposed to hydrogen occurs over the same broad range of stress intensities that cause fatigue when the loads are cycled. Therefore, if a susceptible material is undergoing fatigue, the presence of hydrogen may accelerate fatigue crack growth. Such acceleration has been observed in numerous metals and alloys and example of that effect in HY-80 steel is shown in Figure 27.

The strain rate dependence of hydrogen embrittlement in a tensile test (Figure 19) is consistent with the observations that hydrogen diffusion is a critical factor in the embrittlement process. During fatigue, the time available for hydrogen diffusion will vary with cyclic frequency and wave form. Low cyclic frequencies will provide more time for diffusion and hence more time for subcritical crack growth during each fatigue cycle. An example of the effect of frequency on fatigue crack growth rates in shown in Figure 28. Note that decreasing the cycle frequency from $5 \mathrm{~Hz}$ to $0.05 \mathrm{~Hz}$ increased the fatigue crack growth rate by about an order of magnitude. Similarly, crack opening displacement rates have a major impact on the J-resistance curves for materials tested in hydrogen environments and/or after hydrogen charging. The fracture resistance decreases as the crack opening displacement rates are decreased.

The susceptibility of a material to hydrogen embrittlement is temperature dependent primarily for two reasons:

1) the tendency for hydrogen segregation to regions of lattice dilation decreases as the temperature increases, and

2) the mobility of hydrogen decreases as the temperature decreases.

These two effects combine to maximize embrittlement susceptibility at an intermediate temperature. The temperature of maximum embrittlement susceptibility varies with alloy and metallurgical condition. Although this maximum is often near room temperature it is rarely at room temperature. Many steels (austenitic, ferritic and pearlitic) are most susceptible to embrittlement at temperatures around $260 \mathrm{~K}$. This observation demonstrates that room temperature test results are not generally conservative for steels used at lower temperatures. The temperature of maximum embrittlement susceptibility may also be above room temperature, thus a failure analyst must carefully consider the application of room temperature test results to in-service failures when the failed component was exposed over a range of service temperatures.

The effects of alloy strength and hydrogen content on the susceptibility of a metal or alloy to hydrogen embrittlement may be rationalized through the phenomenological model for embrittlement shown in Figure 29. Four general observations are used in presenting this model:

1) absorbed hydrogen raises the yield strength of the metal (line A in Figure 29),

2) hydrogen in the metal lowers the strength of various metallurgical interfaces (line B in Figure 29),

3) service loads on the metal place localized regions of a component under stresses that initially equals the hydrogen free yield strength (line $C$ in figure 29), and

4) hydrogen in the metal will diffuse to the regions of maximum lattice dilation during component service. 
Each of these four observations has been made by numerous investigators.

When a hydrogen free component is loaded, even though the macroscopic stresses (and resulting lattice dilations) are concentrated, the fracture strength of the metallurgical interfaces exceeds the yield and ultimate strength of the material. However, if the metal contains hydrogen or if hydrogen is absorbed by the metal during service, the absorbed hydrogen segregates to the highly stresses regions and lowers the interfacial strengths. Although line B is shown as representing "the interfacial strength", the various metallurgical interfaces will have different strengths and line B should be divided into numerous lines that represent the different responses of the various interfaces (grain boundaries, particle-matrix, twin boundaries, dislocation arrays, etc.). In fact, the line for one type of grain boundary will probably differ from the line for another type of grain boundary as suggested by the radiographic darkening see in Figure 21. In any event, the hydrogen in the component will diffuse to the high stressed regions and increase the yield strength and lower the interfacial strength in that area. The hydrogen induced increase in yield strength will not weaken the metal and will basically have no adverse effects on the component. However, as the hydrogen content in the localized region increases, the strengths of the interfaces decrease and given sufficient time and a sufficient hydrogen supply, the interfacial strength will decrease until it is lower than stress acting in that region (line B crosses line C). At this point, the hydrogen enriched zone will crack with the crack path following the lowest strength interfaces. The crack will stop when it moves from the hydrogen enriched zone and the enrichment/cracking process will be repeated.

Several other general observations may be made using Figure 29. When the strength of a specific alloy is increased, lines A and C shift to higher stress levels while line B is basically unaffected. The combined effects of these line shifts is that line $\mathrm{B}$ will cross line $\mathrm{C}$ at a lower hydrogen concentration and the embrittlement process occur faster thus suggesting that increasing the strength of a component is not a suitable technique to address a hydrogen embrittlement problem. The change in slope in line B is shown because hydrogen embrittlement testing has shown that hydrogen induced effects saturate at some alloy dependent, hydrogen concentration. Because of the saturation, line $\mathrm{B}$ will not cross line $\mathrm{C}$ if the strength of the alloy is sufficiently low. This observation suggests that low strength alloys may not be susceptible to hydrogen induced damage, an observation that is consistent with the API recommendations that the hardness of alloys used in hydrogen service be kept below about HRC-30.

Hydrogen in a service environment may also adversely alter the properties of metals and alloys. Tensile, creep and fatigue tests have shown that hydrogen in the test environment will decrease the tensile ductility, increase fatigue crack growth rates and accelerate creep. Decades ago, there was a tendency to divide hydrogen embrittlement into two categories: internal hydrogen embrittlement and environmental hydrogen embrittlement. However, because of hydrogen-dislocation interactions, dislocation transport of hydrogen and hydrogen enhanced dislocation emission it is difficult to separate the two categories. Environmental hydrogen embrittlement is important to the failure analyst because hydrogen in the test/service environment will increase the susceptibility of metals and alloys to hydrogen damage. In fact, many metals and alloys that contain no hydrogen will show surface cracks and reduced ductility when tested in hydrogen gas. The surface cracks generally propagate from surface defects such as machine marks and the tendency for such cracking can be reduced by polishing the surface of the test material. The surface cracks on a 
tensile specimen, the increase in fatigue crack growth rates and the acceleration of creep are consistent with hydrogen enhancing dislocation emission from metallic surfaces. These effects, regardless of the operative mechanism, add to any effect that internal hydrogen may have on the properties of the material. Internal and environmental hydrogen embrittlement are simply different paths for hydrogen accumulation in high stressed regions of a metal. When both paths are operating, the susceptibility of a metal to embrittlement is maximized.

Sources of internal hydrogen include hydrogen absorbed during melting and casting operations, hydrogen uptake from acid cleaning or during welding, hydrogen uptake during electroplating and hydrogen uptake from in-service corrosion. To combat the adverse effects of such uptake the Society of Automotive Engineers, the Industrial Fasteners Institute and the American Welding Society and other professional societies cooperate with the ASTM to develop standards for testing for hydrogen embrittlement and standards for bake out techniques to remove hydrogen from electroplated fasteners and other electroplated components. Additionally, there are tools for measuring the hydrogen content of several metals and alloys. However, the correlations between measured hydrogen content and embrittlement are not yet sufficient to assure against hydrogen induced damage and any investigation of a potential hydrogen embrittlement problem should include determinations of what bake-out procedures were used and considerations of what quality control was established to assure against hydrogen embrittlement.

There are three fundamental points that a failure analyst should recognize when addressing a potential hydrogen embrittlement. First, because of the importance of hydrogen content, metallurgical condition, surface conditions, temperature, time and other material/service variables, it is unlikely that test results are available to duplicate in-service behavior. This is especially true if the component was exposed to temperatures other than room temperature. Second, although fractography is important and may even be vital to the investigation, fractography alone cannot be used to determine whether or not hydrogen embrittlement has occurred. Third, solutions to a hydrogen embrittlement problem may involve modifying the material by heat treatment or alloy selection, changing the manufacturing process, changing the hydrogen out gassing or bake out procedures and changing the component design. Each of these factors should be considered before making recommendations to the customer.

\section{Summary}

This primer outlined five specific types of hydrogen induced damage to metals and alloys. These types are: hydrogen embrittlement, hydrogen-induced blistering, cracking from precipitation of internal hydrogen, hydrogen attack, and cracking from hydride formation. Each of these categories of hydrogen damage is presented and both specific and general examples are discussed.

\section{Acknowledgements}

This paper summarizes knowledge gained through approximately fifty years of studying the effects of hydrogen on metals and alloys. The primary place of study has been during a total of $30+$ years the Savannah River National Laboratory. I was first introduced to hydrogen embrittlement in 1958 
when an undergraduate student at Virginia Polytechnic Institute. My first opportunity to publish in the hydrogen in metals arena came in 1961 and since that time I have been privileged to work on hydrogen induced damage problems at the University of Notre Dame, Sandia National Laboratory and Virginia Polytechnic Institute and State University as well as at SRNL. My colleagues and my students have been extraordinarily knowledgeable and supportive, my employers have provided wonderful working environments, excellent facilities and technical libraries and allowed for the travel, conference attendance and networking necessary to participate in the evolution of our understanding of hydrogen embrittlement processes. My wife, Fran, has put up with my interest hydrogen embrittlement, accompanied my travels and provides support far beyond a normal call to duty. This paper lacks the appropriate references because I lack the organizational skills necessary to catalogue and retrieve papers, manuscripts and proceedings. Many of the ideas presented were not mine but were heard, read or seen when others were presenting their work. I apologize for the lack of references; however, the reports used to obtain many of the Figures in this manuscript are referenced and the books that contain those papers discuss most of the ideas presented and a few excellent ideas that I didn't discuss. When confronted, I will willingly admit that the good ideas in this manuscript may be yours and that the mistakes are all mine.

\section{References}

1) ASM Materials Handbook, Metals Handbook, Ninth Edition, Volume 13, Corrosion, ASM International, Materials Park, OH, 1987

2) ASM Materials Handbook, Metals Handbook, Ninth Edition, Volume 11, Failure Analysis and Prevention, ASM International, Materials Park, OH, 1986

3) M. R. Louthan, Jr., "Effects of Hydrogen on the Mechanical Properties of Low Carbon and Austenitic Steels", Hydrogen in Metals, I. M. Bernstein and A. W. Thompson, Editors, page 53-77, American Society for Metals, Metals Park, OH, 1974

4) M. R. Louthan, Jr., G. R. Caskey, Jr., J. A. Donovan and D. E. Rawl, Jr., "Hydrogen Embrittlement of Metals", page 289-300, Hydrogen Damage, C. D. Beachem, Editor, American Society for Metals, Metals Park, OH, 1977

5) J. E. Stiner, "Control of Flaking and Other Hydrogen Problems in Heavy Forgings", page 55-62, Current Solutions to Hydrogen Problems in Steels, C. G. Interrante and G. M. Pressouyre, Editors, American Society for Metals, Metals Park, OH, 1982

6) T. A. Parthasarathy, H. F. Lopez and P. G. Shewmon, "Hydrogen Attack Kinetics of 2.25 Cr-1 Mo Steel Weld Metals", Mat. Trans. A, Volume 16A, page 1143, 1985

7) E. D. D. During, Corrosion Atlas, A Collection of Illustrated Case Histories, Elsevier, The Netherlands, 1997

8) G. A. Nelson, "Hydrogenation Plant Steels", page 377-394, Hydrogen Damage, C. D. Beachem, Editor, American Society for Metals, Metals Park, OH, 1977

9) T. P. Herbell, D. Hull and G. W. Hallum, "Effect of High Temperature Hydrogen on the Strength and Microstructure of Mullite", page 351-359, Hydrogen Effects on Material Behavior, N. E. Moody and A. W. Thompson, Editors, TMS, Warrendale, PA, 1990

10) ASM Handbook, Volume 3, Alloy Phase Diagrams, ASM International, Materials Park, $\mathrm{OH}, 1992$

11) M. R. Louthan, Jr. and R. P. Marshall, "Control of Hydride Orientation in Zircaloy”, page 170, Journal of Nuclear Materials, Vol. 9, 1963 
12) H. G. Nelson, "Effect of High Temperature Hydrogen on Titanium Base Alloys", page 699-717, Hydrogen Effects in Materials, A. W. Thompson and N. E. Moody, Editors, TMS, Warrendale, PA, 1996

13) A. W. Thompson and I. M. Bernstein, "Microstructure and Hydrogen Embrittlement", page 291-308, Hydrogen Effects in Metals, I. M. Bernstein and A. W. Thompson, Editors, The Metallurgical Society of AIME, Warrendale, PA, 1981

14) J. P. Laurent, G. Lapasset, M. Aucouturier and P. Lacombe, "The Use of High Resolution Autogadiography in Studying Hydrogen Embrittlement”, Hydrogen in Metals, I. M. Bernstein and A. W. Thompson, Editors, page 559-574, American Society for Metals, Metals Park, OH, 1974

15) K. Yoshino and C. J. McMahon, Jr., "The Cooperative Relation between Temper Embrittlement and Hydrogen Embrittlement in a High Strength Steel", page 311-318, Hydrogen Damage, C. D. Beachem, Editor, American Society for Metals, Metals Park, $\mathrm{OH}, 1977$

16) A. R. Troiano, "The Role of Hydrogen and Other Interstitials in the Mechanical Behavior of Metals", page 151-177, Hydrogen Damage, C. D. Beachem, Editor, American Society for Metals, Metals Park, OH, 1977

17) C.G. Interrante, "Basic Aspects of the Problems of Hydrogen in Steel", page 3-17, Current Solutions to Hydrogen Problems in Steels, C. G. Interrante and G. M. Pressouyre, Editors, American Society for Metals, Metals Park, OH, 1982

18) R. P. Gangloff, "Diffusion Control of Hydrogen Environment Embrittlement in High Strength Alloys", page 477-499, Hydrogen Effects on Materials and Corrosion Deformation Interactions, N. R. Moody, A. W. Thompson, R. E. Ricker, G. W. Was and R. H. Jones, Editors, TMS, Warrendale, PA, 2003

19) W. G. Clark, "The Effect of Hydrogen Gas on the Fatigue Crack Growth Rate Behavior of HY-80 and HY-130 Steels" Hydrogen in Metals, I. M. Bernstein and A. W. Thompson, Editors, page 149-162, American Society for Metals, Metals Park, OH, 1974

20) S. P. Lynch and N. E. Ryan, "Mechanisms of Hydrogen Embrittlement - Crack Growth in a Low Alloy Ultra-High-Strength Steel Under Cyclic and Sustained Stresses in Gaseous Hydrogen" page 369-376, Hydrogen Damage, C. D. Beachem, Editor, American Society for Metals, Metals Park, OH, 1977 

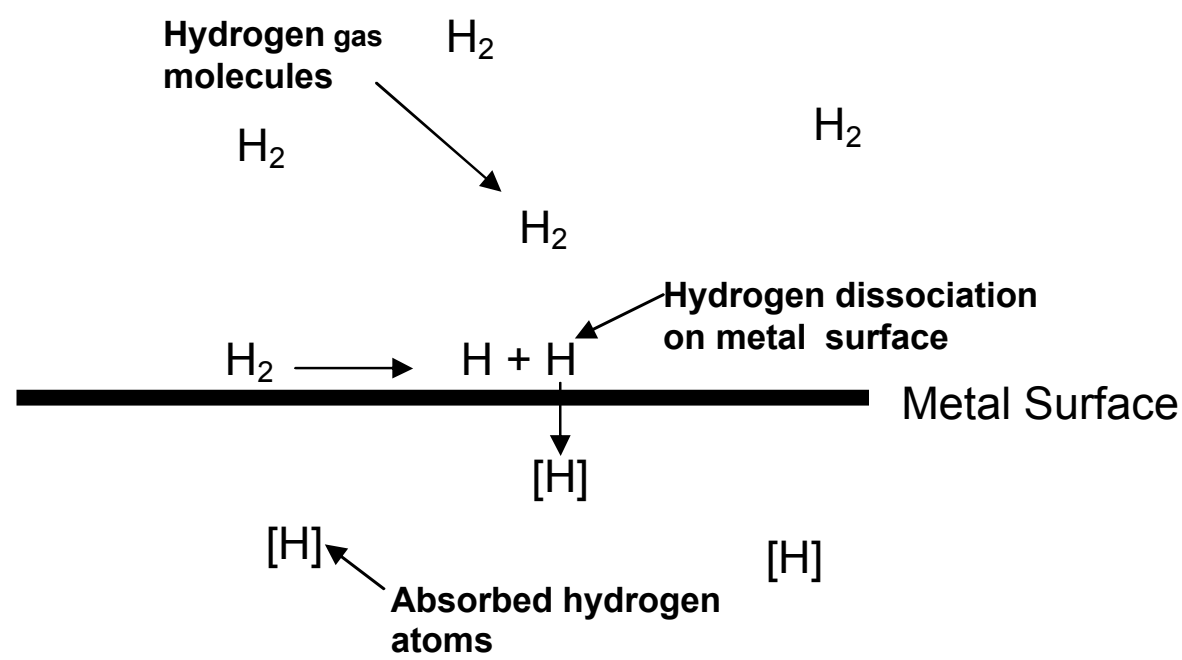

Figure1. Hydrogen Absorption in Metals Exposed to a Gaseous Hydrogen Environment 
WSRC-STI-2008-00062

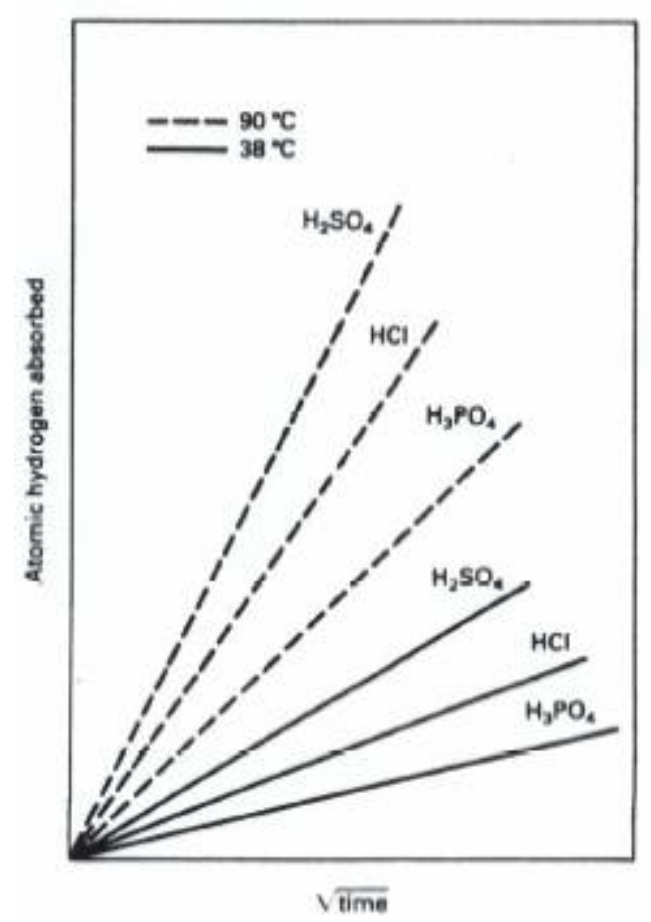

Figure 2. Time and Temperature Effects on Hydrogen Absorption in Metals Exposed to Various Acids. After Figure 6, page 330 of Reference 1.

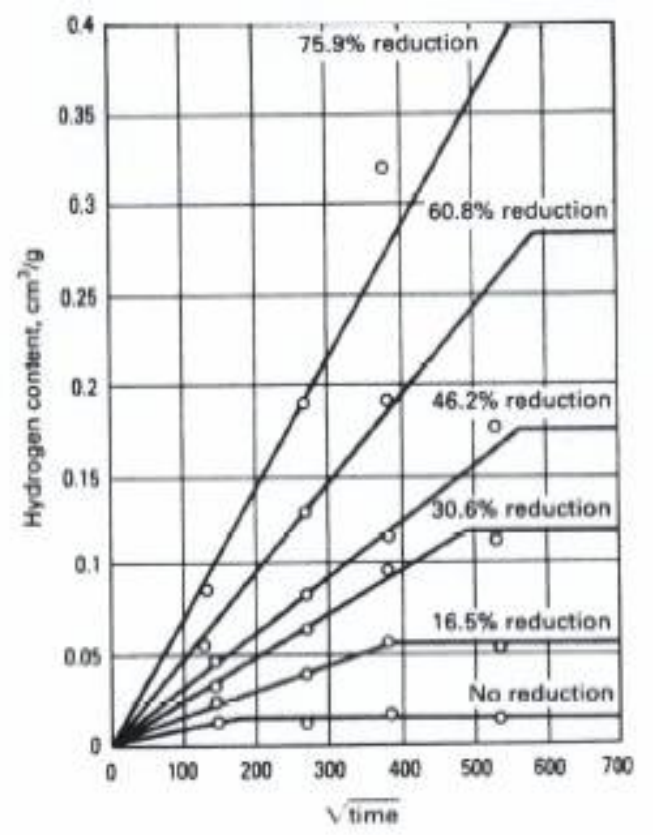

Figure 3. The Effect of Cold Work on Hydrogen Absorption in Carbon Steel Exposed to 1N Sulfuric Acid. A hydrogen content of $0.1 \mathrm{~cm}^{3} / \mathrm{g}$ is approximately $8 \mathrm{ppm}$ by weight. After Figure 2, page 329 of Reference 1. 


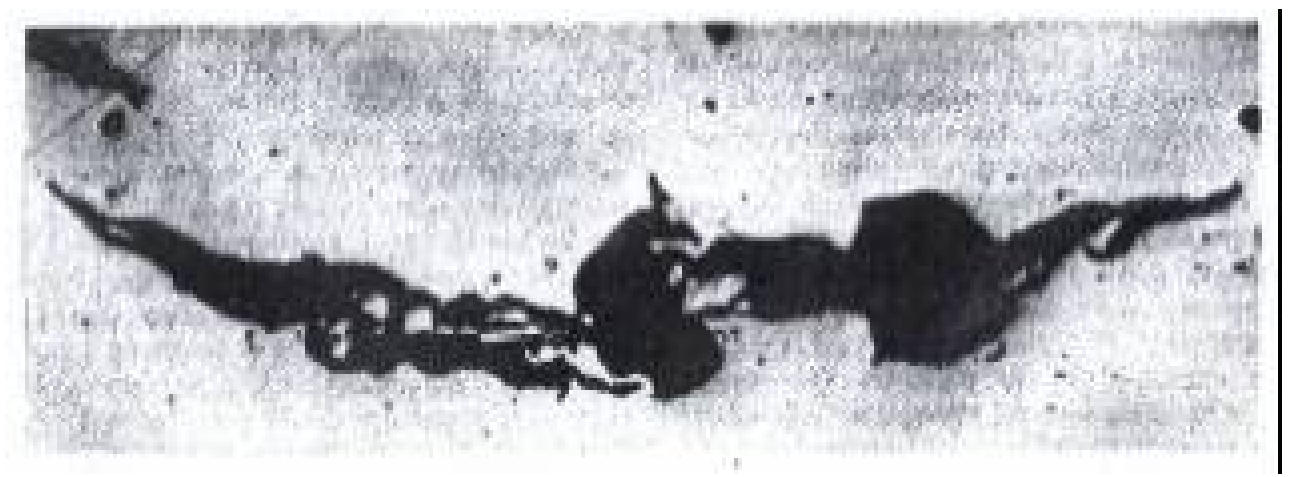

Figure 4. Initiation of a Hydrogen Induced Blister in 1020 Steel. One inch on the photograph equals 0.0025 inches on the actual part. After Figure 3, page 247 of Reference 2

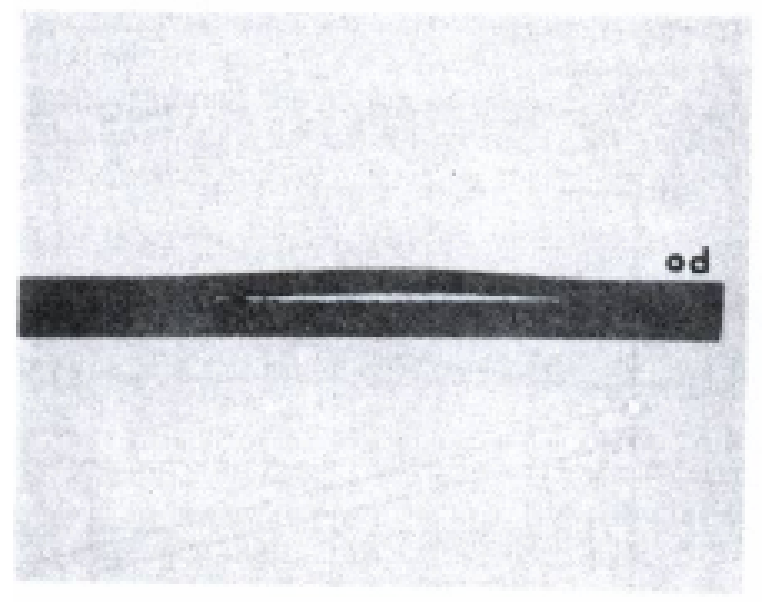

Figure 5. Hydrogen Blister in a $3 / 4$ inch Thick Steel Plate. The plate was in a tank used to store HF and the side of the plate that was outside the tank is marked od. After Figure 10a, page 332 of Reference 1 


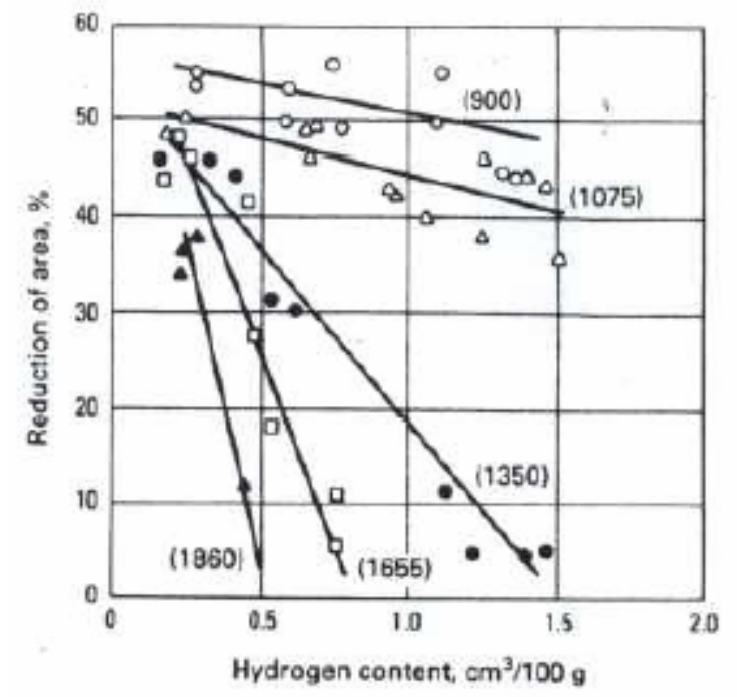

a) Quenched and Tempered Steels Strength Levels in MPa Marked

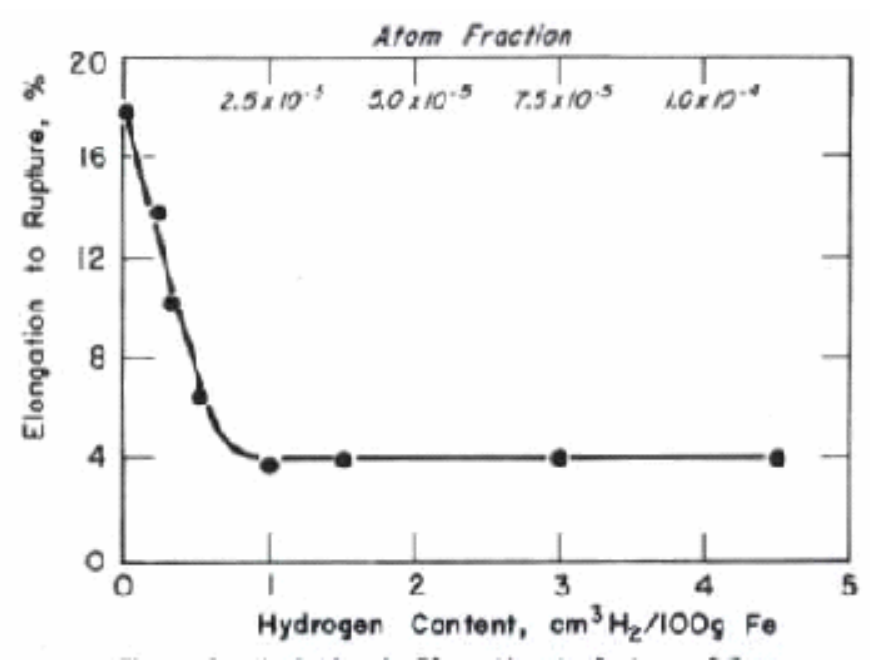

b) Zone Refined Iron

Figure 6. Effect of Hydrogen Content on Ductility of Steels and Zone Refined Iron. After Figure 4, page 330 of Reference 1 and Figure 4, page 57 of Reference 3
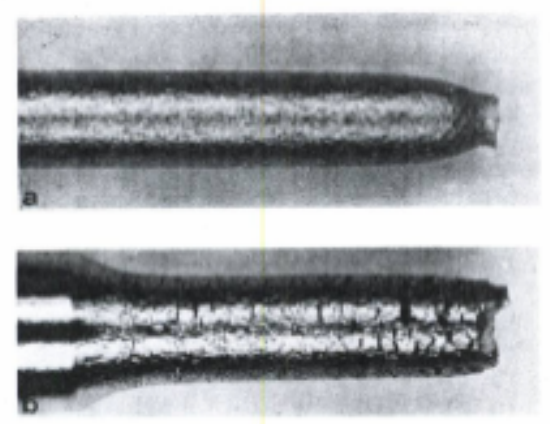

Figure 7. Surface Cracks on Tensile Specimen Strained in the Presence of High Pressure Hydrogen. Type 304L stainless steel tested in 10,000 psi hydrogen at room temperature. The $1 / 4$ inch diameter sample was not exposed to hydrogen prior to initiation of the tensile test. After Figure 5, page 293 of Reference 4. 

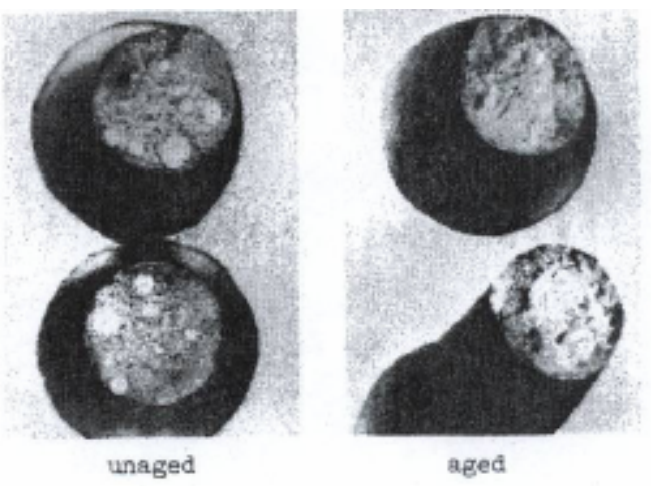

Figure 8. Fracture Surface Appearance Giving Rise to the Term Fisheye. Tensile specimens were 4140 steel. The aged samples were heated to $260 \mathrm{C}$ for one hour to remove the hydrogen. After Figure 8, page 60 of Reference 5.

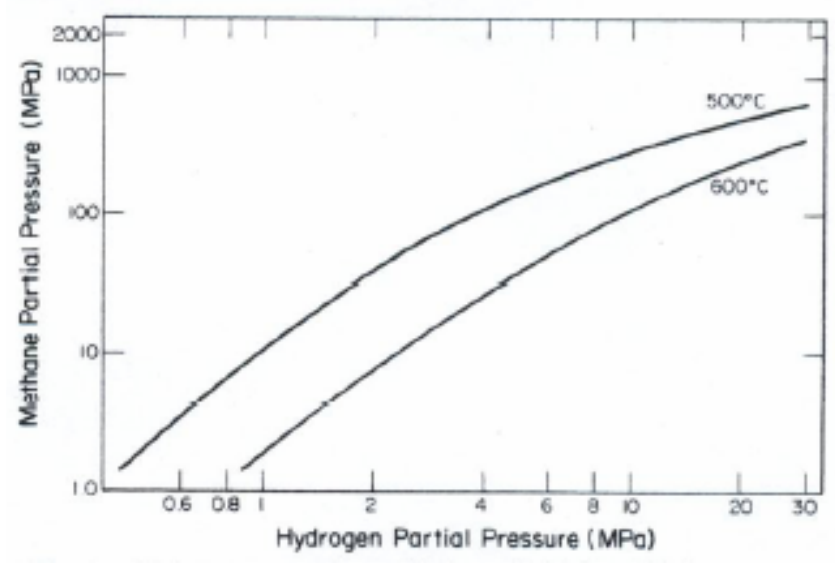

Figure 9. Equilibrium Methane Pressures in a Commercial Quenched and Tempered 2.25Cr-1Mo Steel. After Figure 4, page 1147 of Reference 6. 

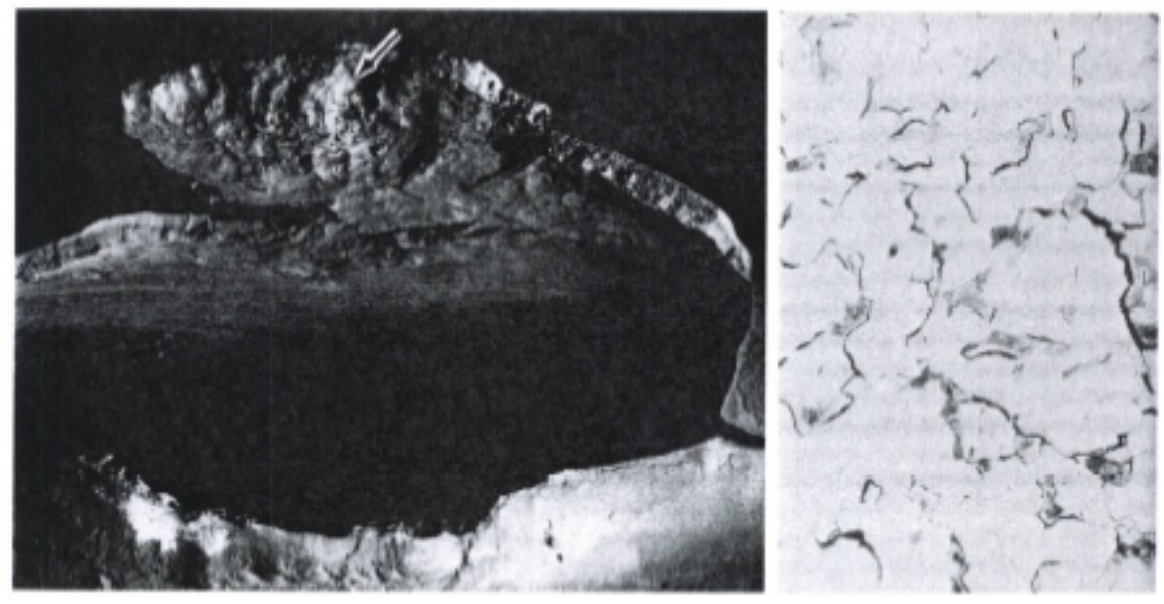

Figure 10. Intergranular Cracking and Rupture due to Hydrogen Attack. After Case History 01.01.20.03, page 39 of Reference 7 

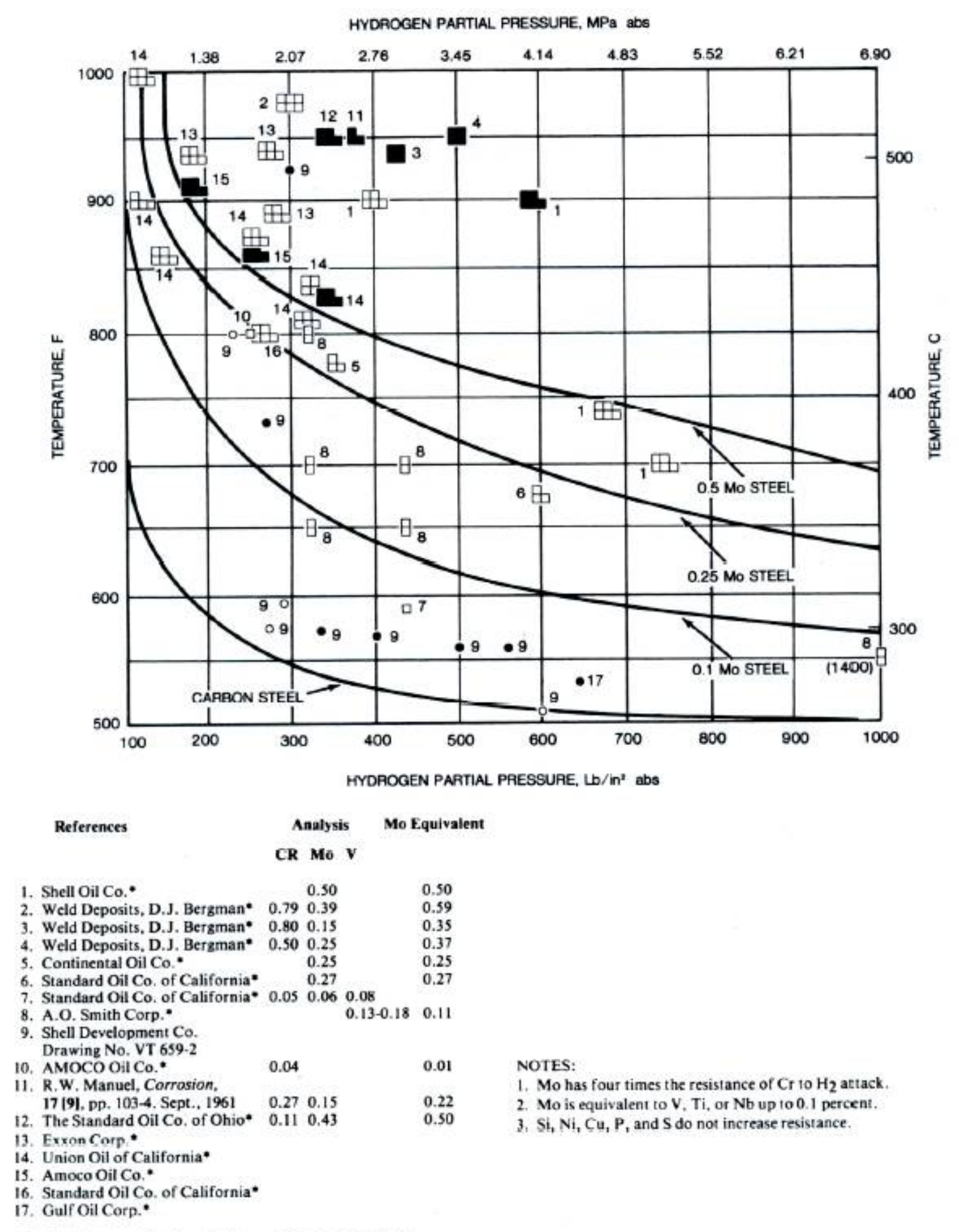

-Private communication to Subcommittee on Corrosion

Figure 11a. Nelson Curve Showing Operating Limits for a Carbon and Low Molybdenum Steels. After Figure 2, page 391 in Reference 8 


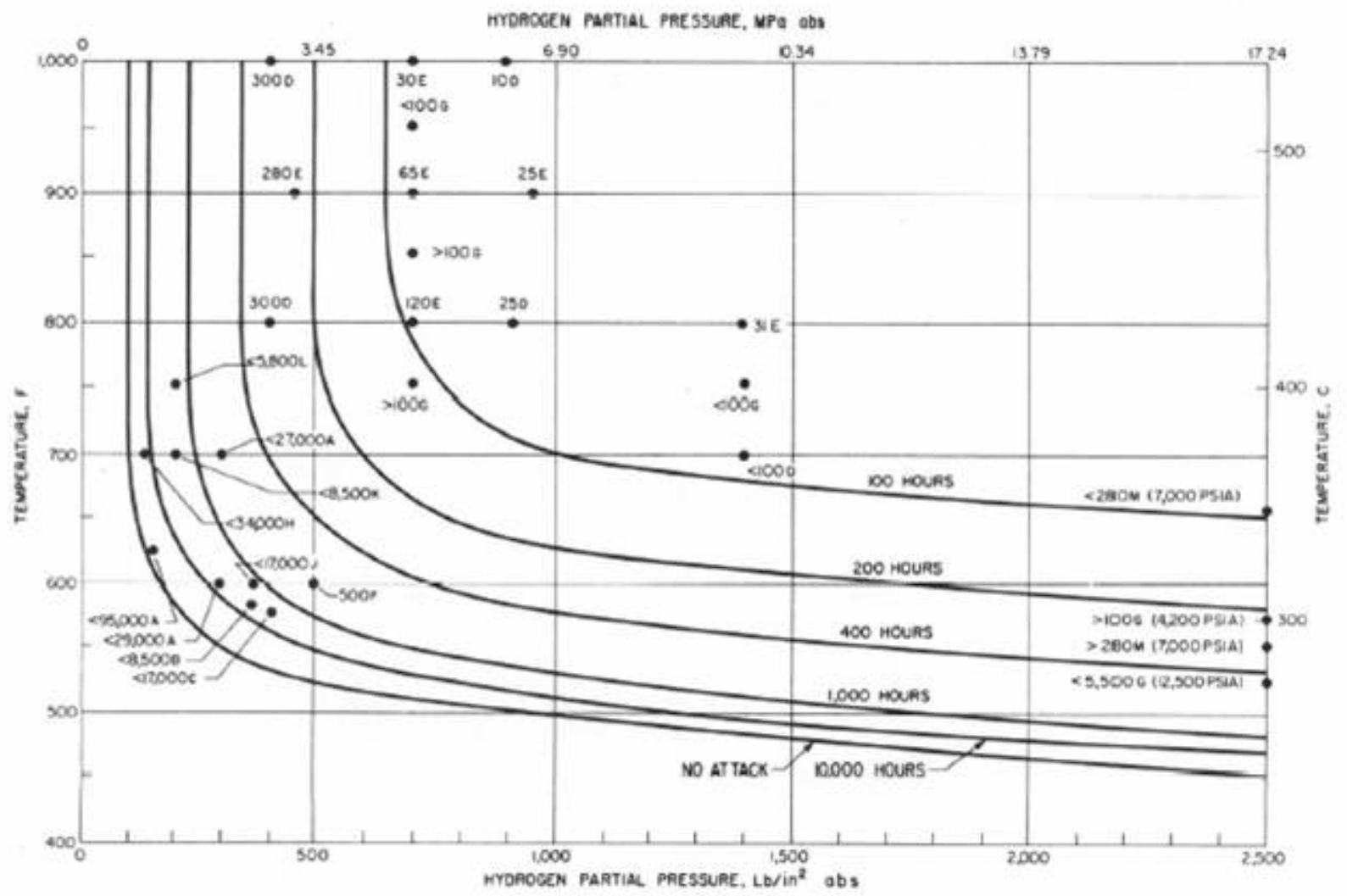

\section{References}

A. AMOCO Oil Co., 1960.

B. A.R. Ciuffreda and W.D. Rowland, "Hydrogen Attack of Steel in Reformer Service," Proc, API, 37 [III], pp. 116-28, 1957.

C. C.A. Zapffe, "Boiler Embrittlement," Trans, ASME, 66, DD. 81-126, Feb, 1944.

D. R.E. Allen, R.J. Jansen, P.C. Rosenthal, and F.H. Vitovec, "The Rate of Irreversible Hydrogen Attack of Stcel at Elevated Temperatures," Proc, API, 41 [III], pp. 74-84, 1961.

E. L.C. Weiner, "Kinetiss and Mechanism of Hydrogen Atteck of Steel," Corrosion, 17, pD. 109-15, 1961.

F. J.J. Hur, J.K. Deichler, and G.R. Worrell, "Building a Catalytic Reformer?" Oit Gas J., 54 [78]. pp. 103-7, Oct. 29, 1956.

G. F.K. Naumann, "Influcnce of Alloy Addition to Steel upon
Resistance to Hydrogen under High Pressure," Tech. Mitr. Krupp, 1 [12], pp. 223-34, 1938 .

H. M. Hasegawa and S. Fujinaga, "Attack of Hydrogen on Oil Refinery Steels," Tetsu To Hagane, 46 [10]. pp. 1349-52, 1960.

J. T.C. Evans, "Hydrogen Attack on Carbon Steels," Mech. Eng., 70, pp, 414-16, 1948.

K. Air Products, Inc., Mar., 1960.*

L. API Refinery Corrosion Comm, survey, 1957,

M. I. Class, "Present State of Knowledge in Resyect to the Properties of Stcels Resistant to Hydrogen under Pressure," Siahl Eisen, 80 Aug. 18. 1960.

-Private communication to Subcommittee on Corrosion

Figure 11b. Importance of Time in the Positioning of Lines on a Diagram Similar to a Nelson Curve. After Figure 3, page 392 of Reference 8 
WSRC-STI-2008-00062

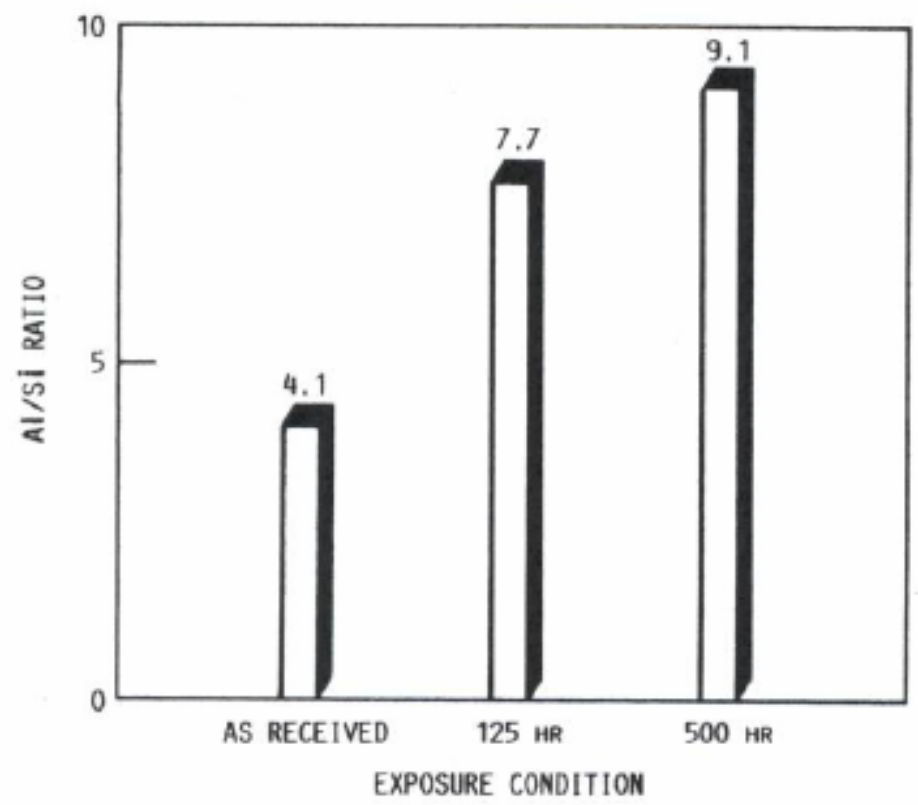

Figure $12 \mathrm{Al} / \mathrm{Si}$ Ratio at the Surface of Mullite Exposed to Hydrogen Gas at $1250 \mathrm{C}$. After Figure 3, page 355 of Reference 9 


\section{H-Ti}

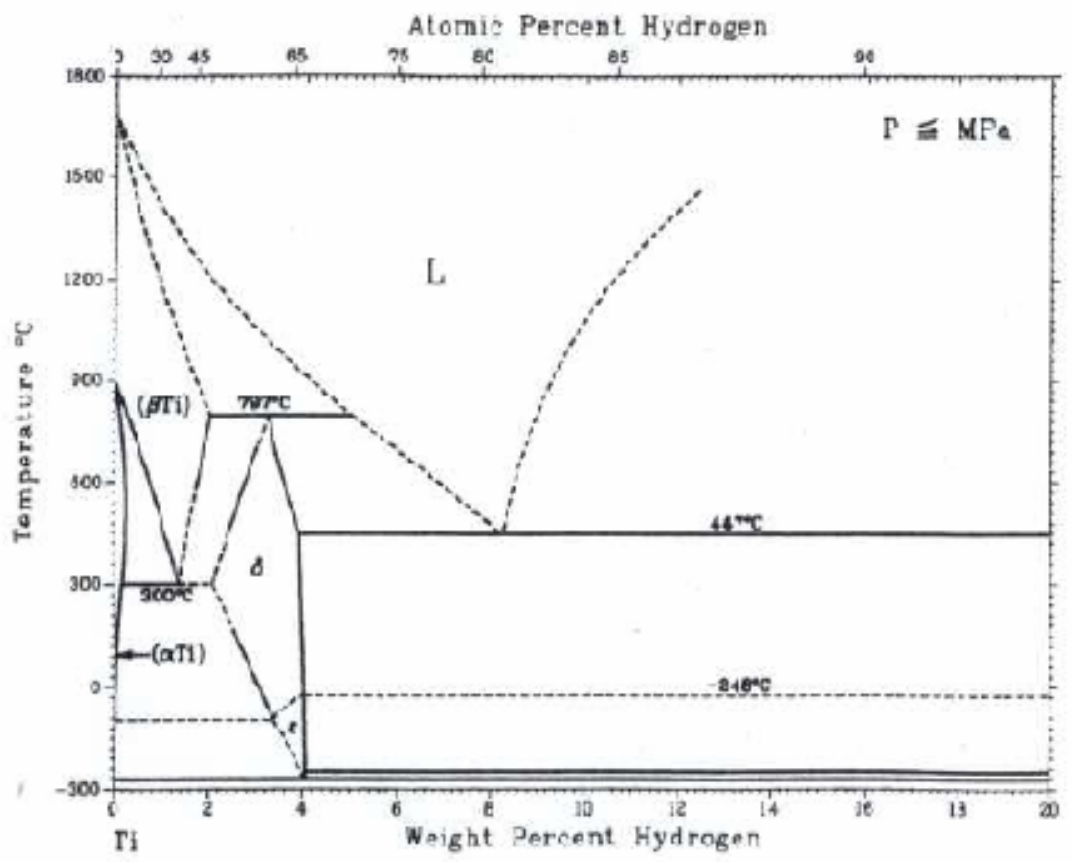

a) A Hydride Forming Metal (Titanium)

\section{$\mathrm{Fe}-\mathrm{H}$}

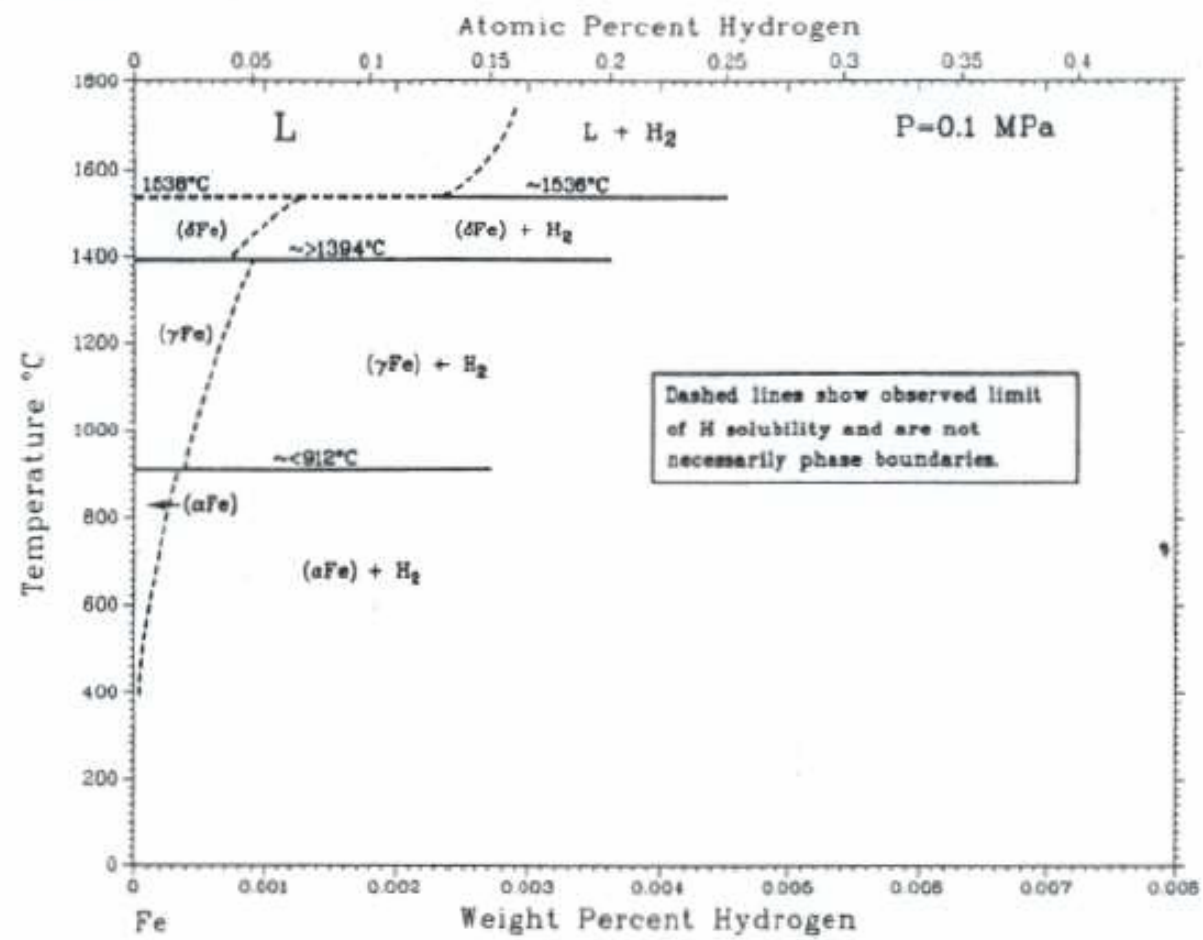

b) Non-Hydride Forming Metal (Iron)

Figure 13 Hydrogen-Metal Phase Diagrams. After the H-Ti phase diagram on page 238 and the Fe$\mathrm{H}$ phase diagram on page 195 of Reference 10 
¿ Tensile stress $\rightarrow$

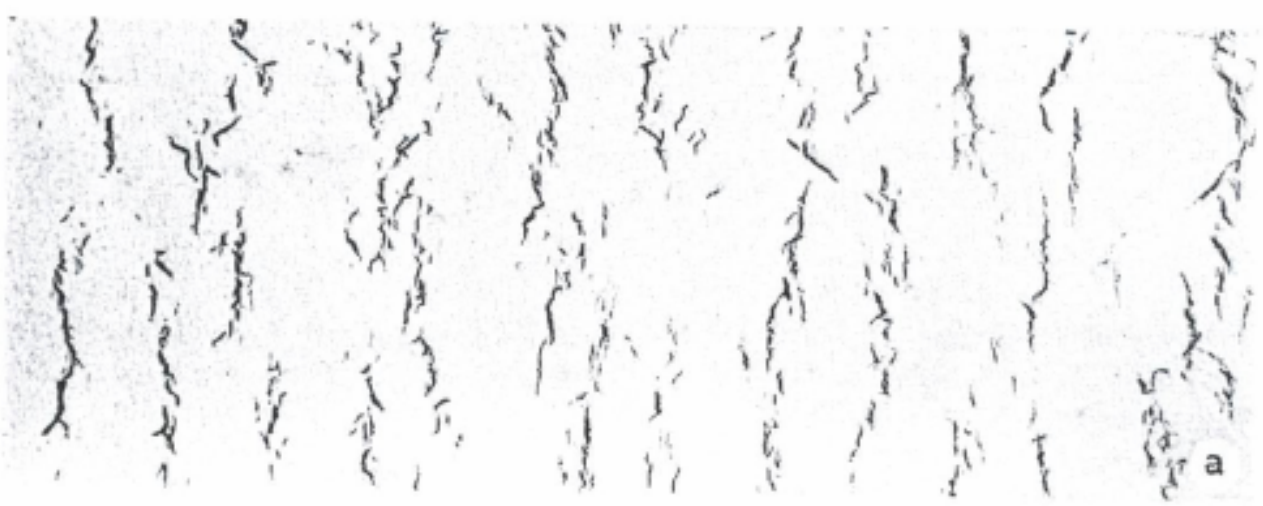

a) Hydride Precipitation in Stressed Sample

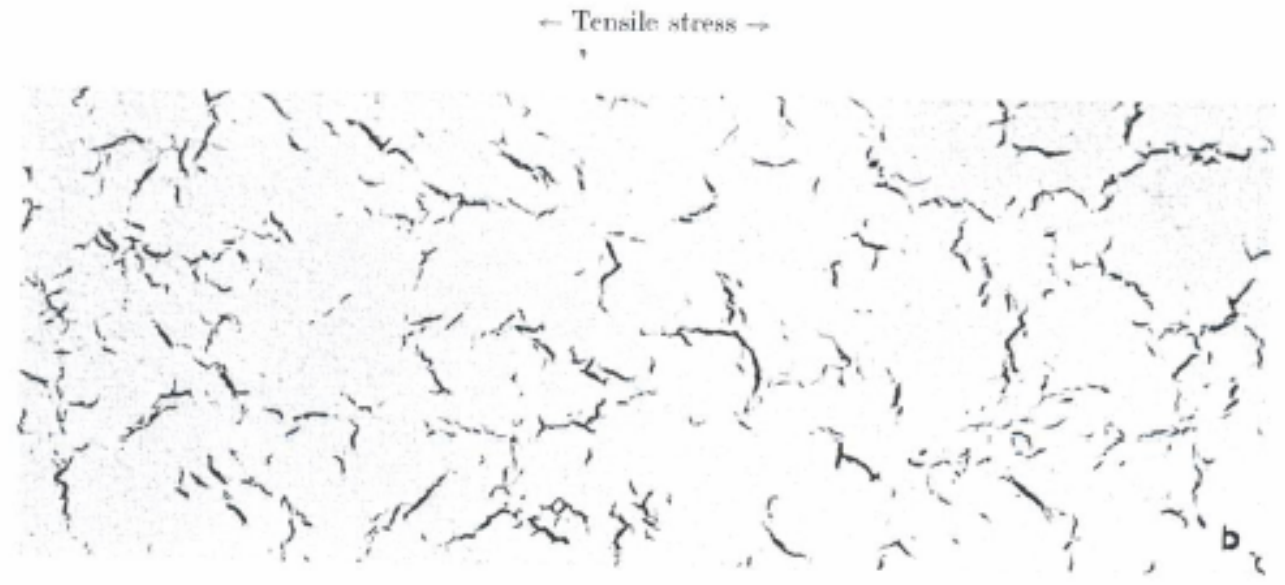

b) Hydride Precipitation in Non-stressed Sample

Figure 14. Stress Orientation of Hydrides in Zircaloy-2 Cladding. After Figure 15, page 182, of Reference 11 


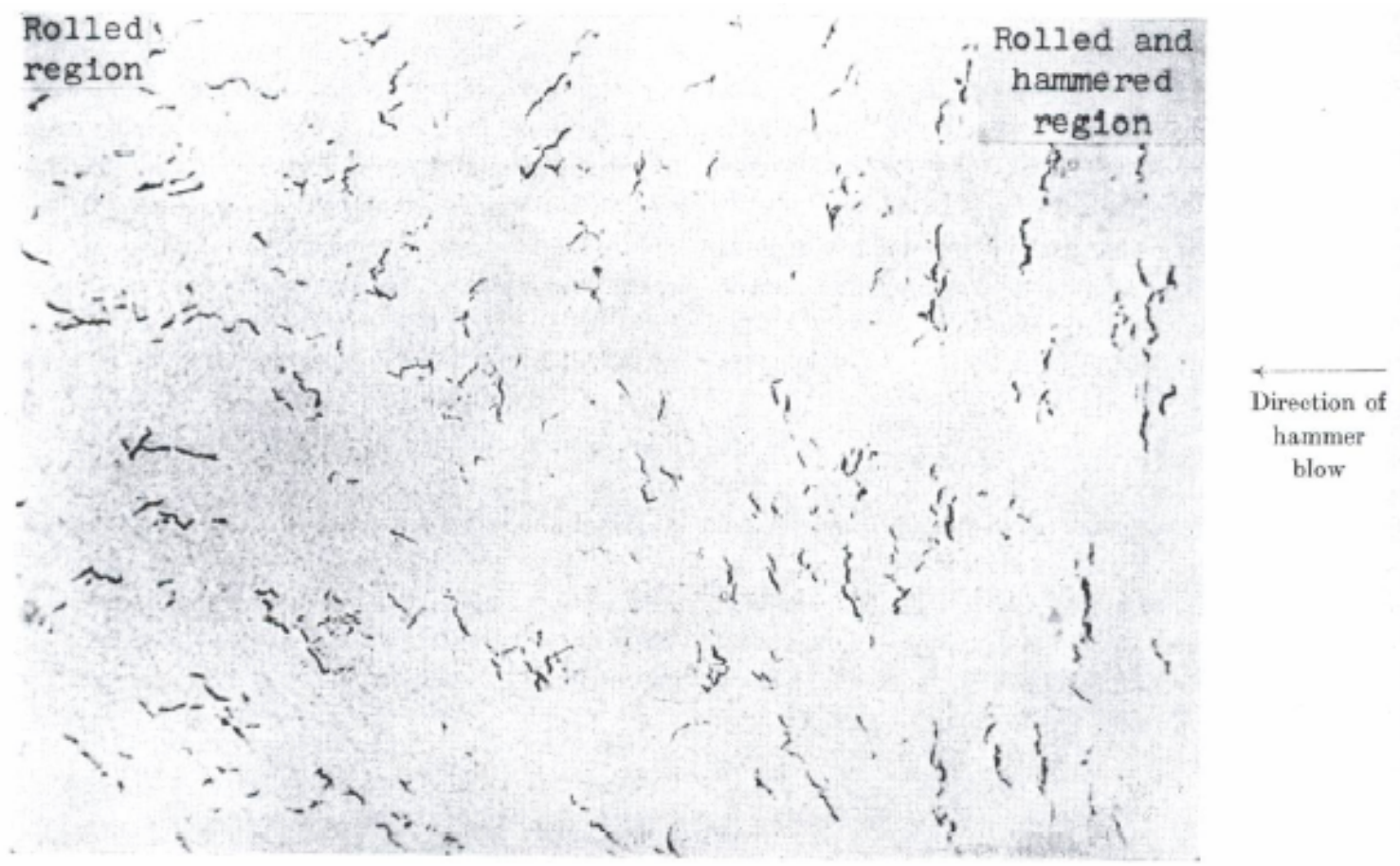

Figure 15. Strain Orientation of Hydrides in Zircaloy-2 Plate. Hydride orientation in rolled plate that was hammered on one end and then hydrided. After Figure 13, page 181 of Reference 11

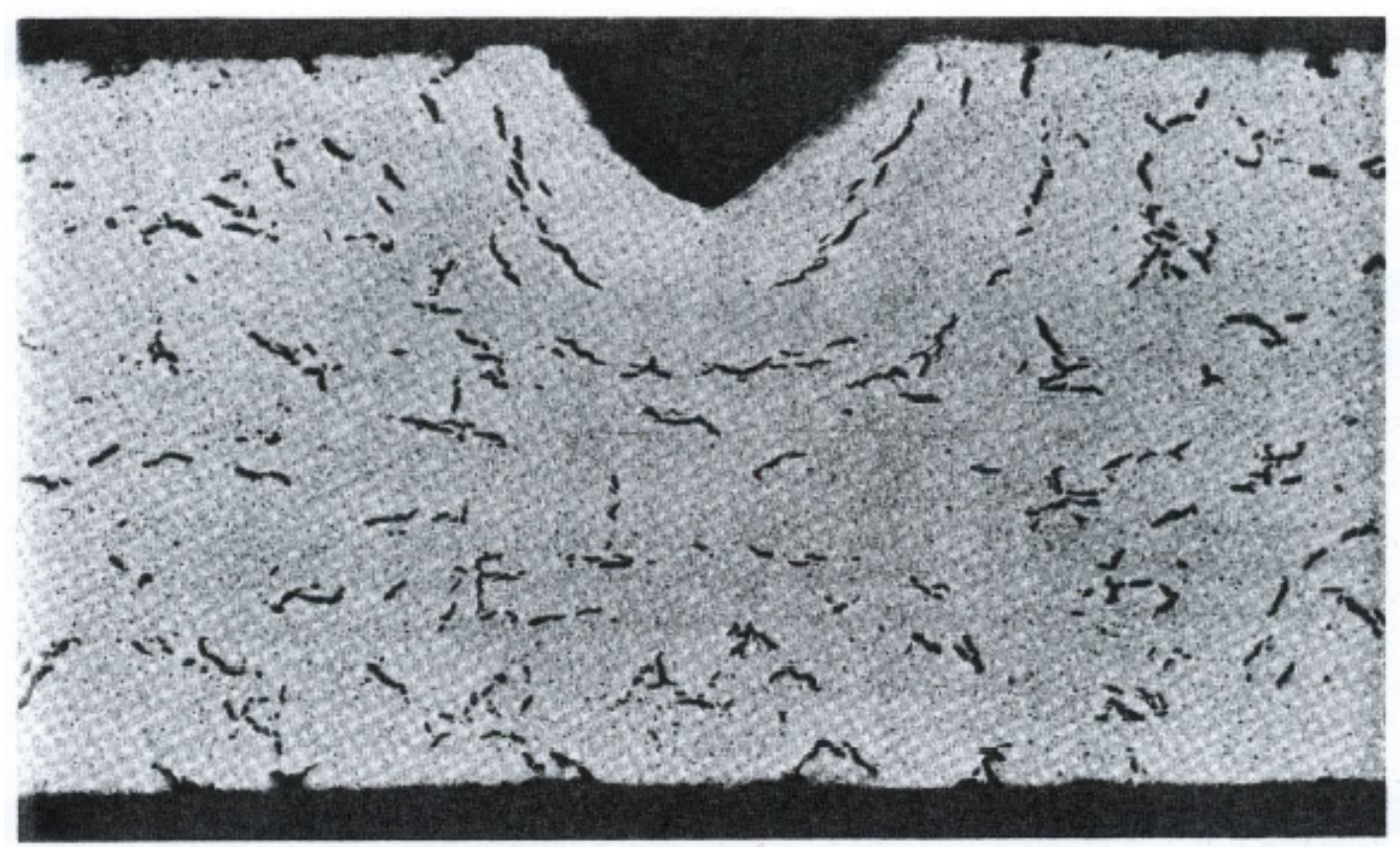

Figure 16. Hydride Reorientation at Room Temperature. The notch was placed on a 30 mil thick tensile specimen which was then sectioned and examined without ever heating the specimen above room temperature. After Figure 11, page 179 of Reference 11 
WSRC-STI-2008-00062

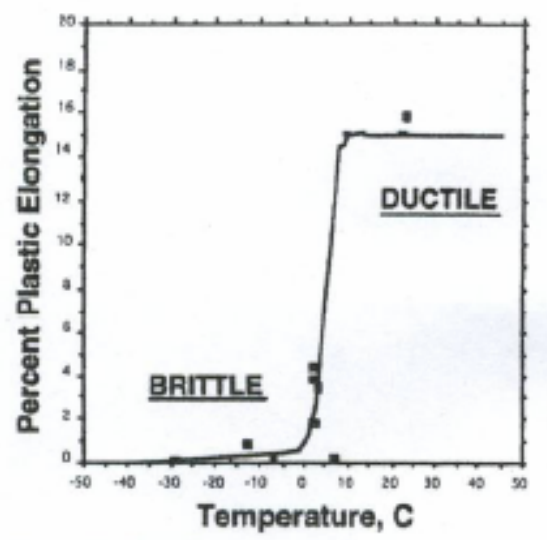

Figure 17. Ductile to Brittle Transition in Hydrogen Charged Timet 21S, a Beta Titanium Alloy. After Figure 8, page 709 of Reference 12

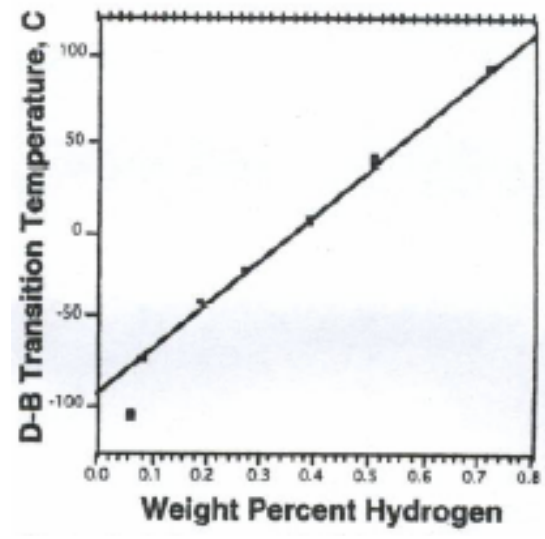

Figure 18 Influence of Hydrogen Content on the Ductile-to-Brittle Transition Temperature of Timet 21S. After Figure 9, p709, of Reference 12 
WSRC-STI-2008-00062

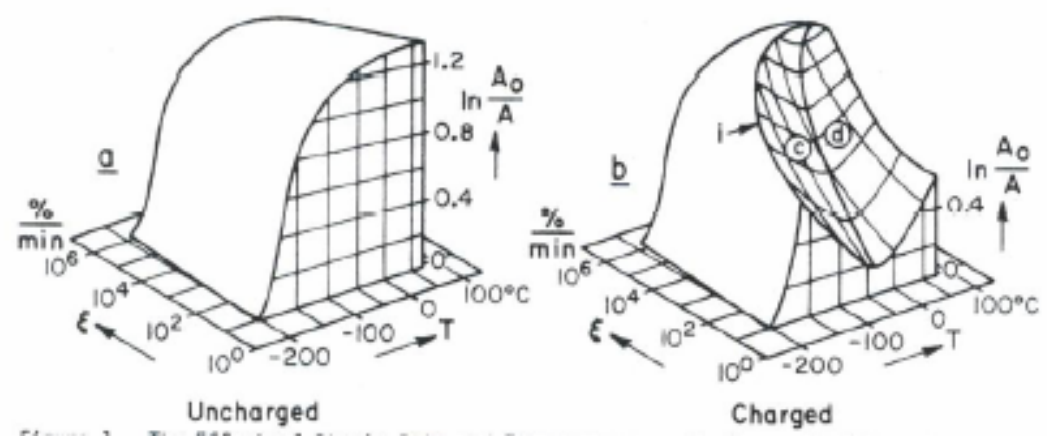

Figure 19. The Effect of Test Temperature and Strain Rate on the Susceptibility of Mild Steel to Hydrogen Embrittlement. After Figure 1, page 56 of Reference 3 (original work by Toh and Baldwin)

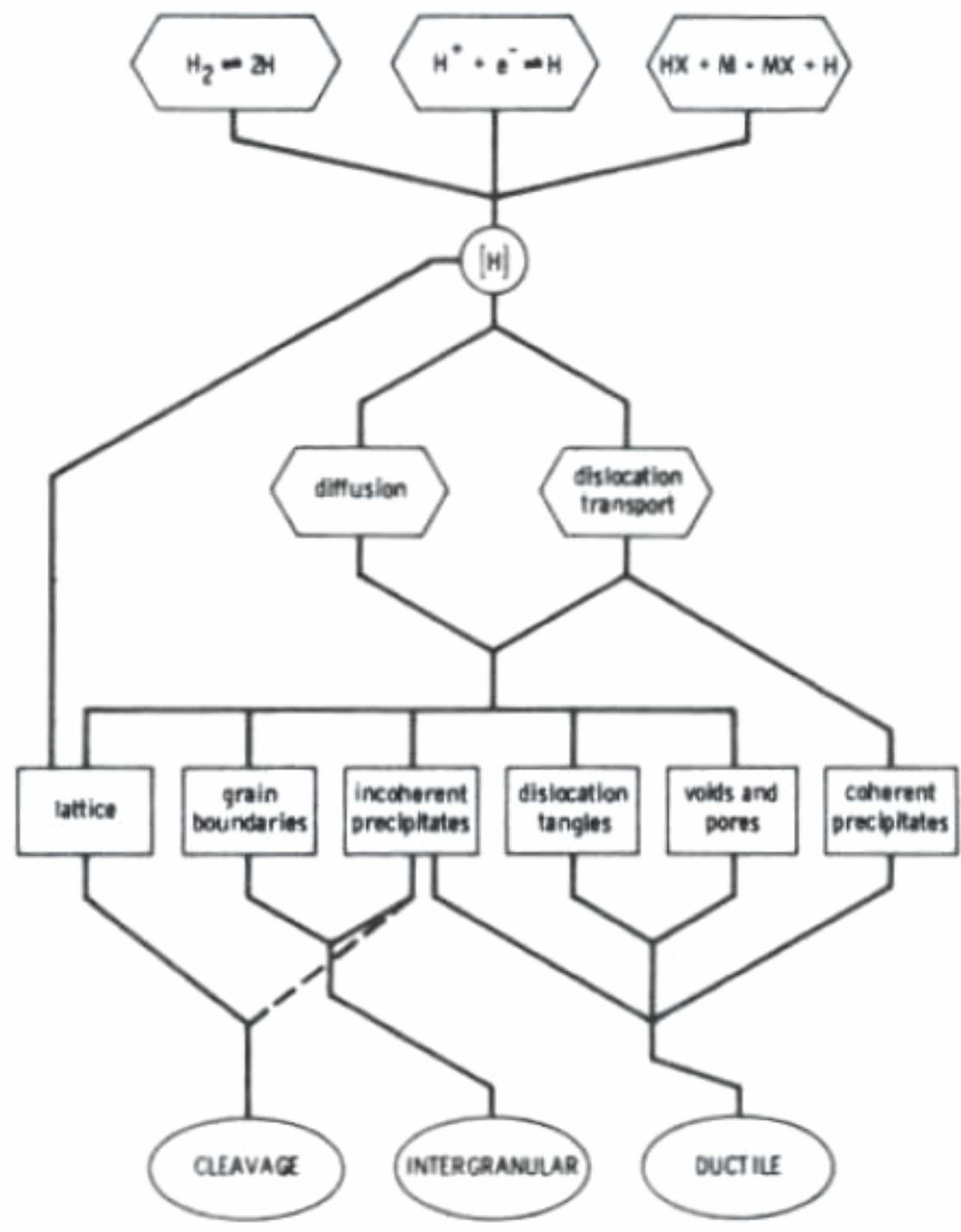

Figure 20. Schematic of Some of the Processes and Microstructural Variables Involved in Hydrogen Embrittlement. After Figure 15, page 304 of Reference 13 
WSRC-STI-2008-00062

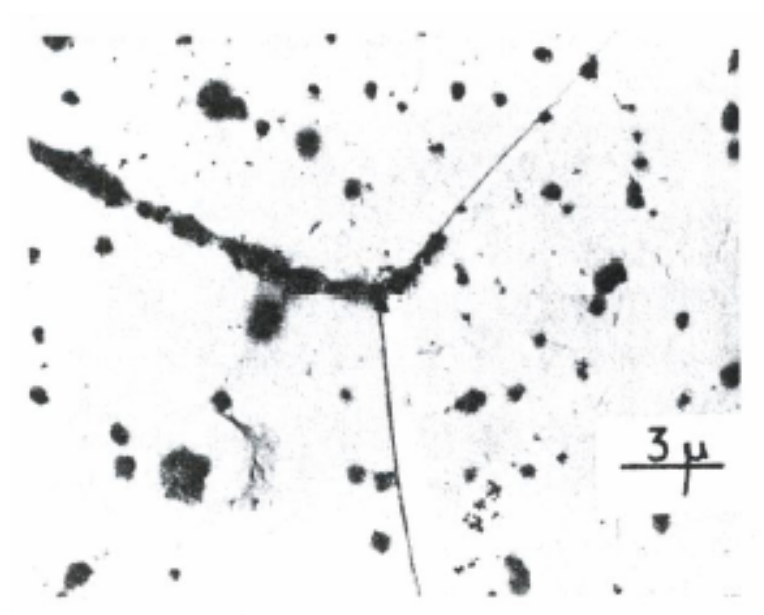

Figure 21. Autoradiograph Showing Tritium Segregation to Grain Boundaries in Iron. The dark spots are regions of high hydrogen concentration - note that one grain boundary has a higher hydrogen content than the other boundaries. After Figure 2, page 562 of Reference 14

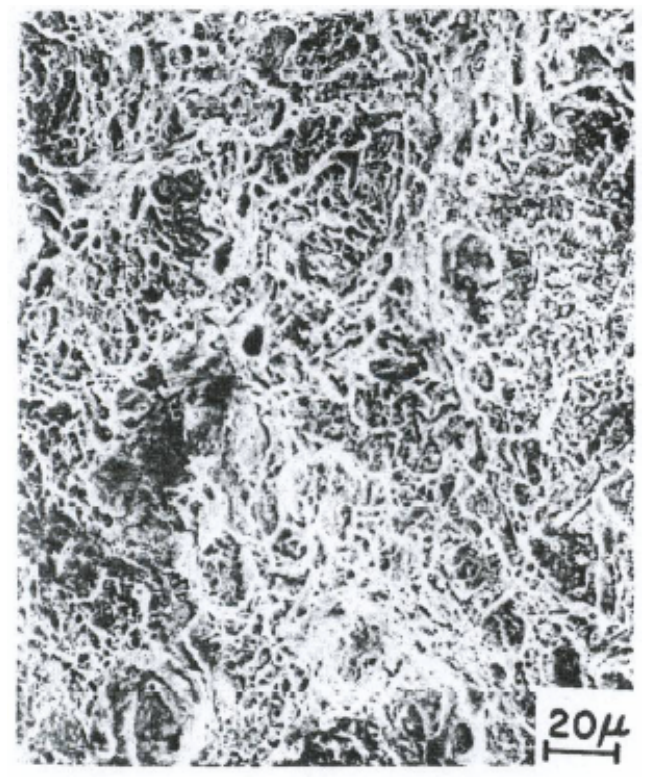

a) hydrogen embrittlement

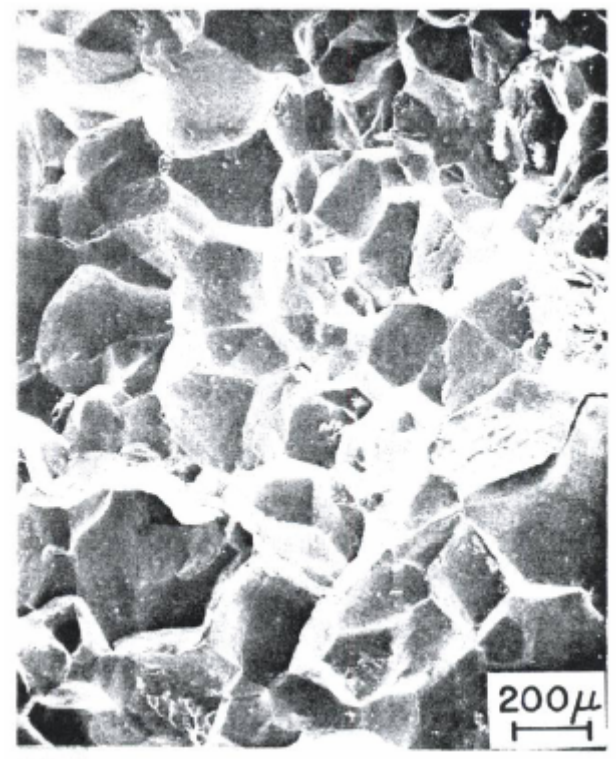

b) temper embrittlement

Figure 22 Fractographic Features of Hydrogen Assisted Cracking and Temper Embrittlement in an HY-130 Steel. Note that the hydrogen embrittlement fracture, a), is characterized by ductile rupture while the temper embrittlement fracture, b), is characterized by intergranular rupture. After Figure 4d, page 313 and Figure 8b, page 315 of Reference 15 
WSRC-STI-2008-00062

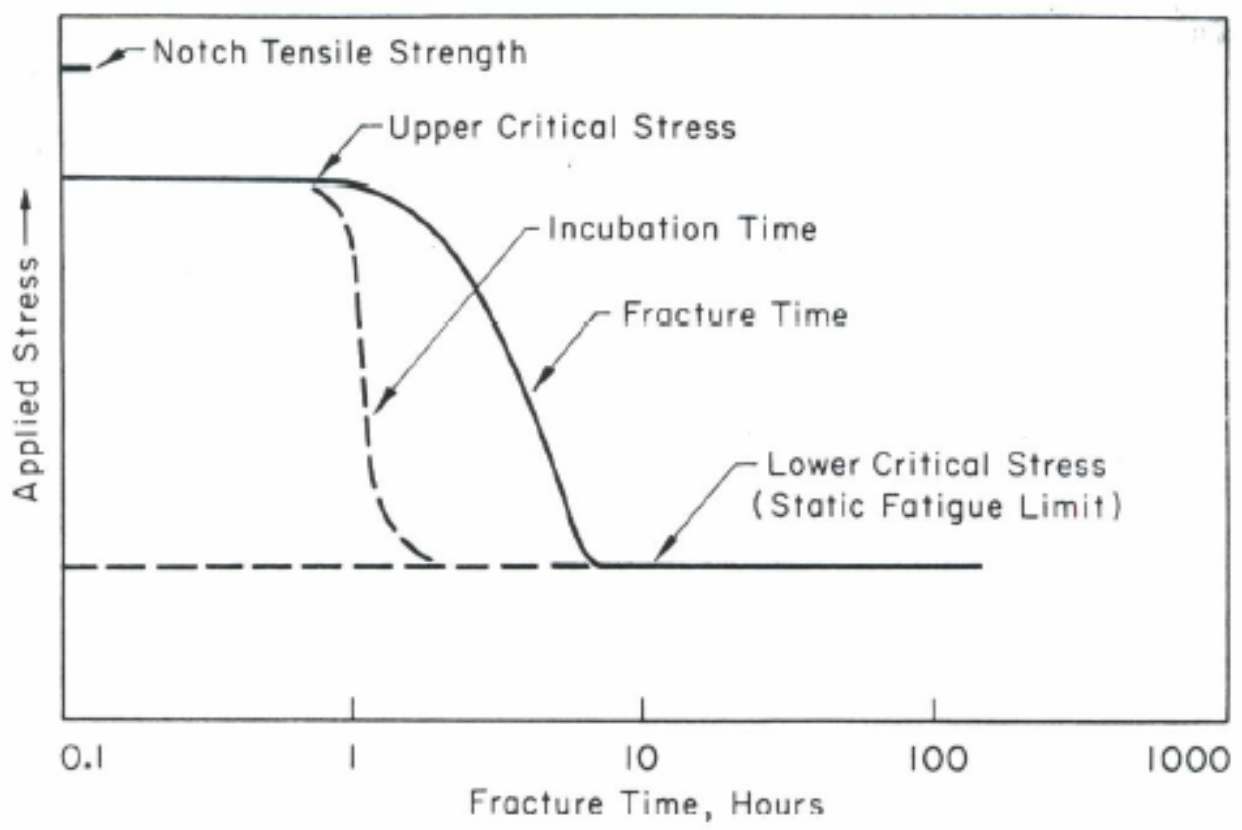

Figure 23. Schematic Illustration of the Stress/Time Dependence of Hydrogen Embrittlement. The stress levels and times required for the hydrogen embrittlement processes vary with exposure temperature, hydrogen content, metallurgical condition and effectiveness of the stress concentration. After Figure 1, page 153 of Reference 16 


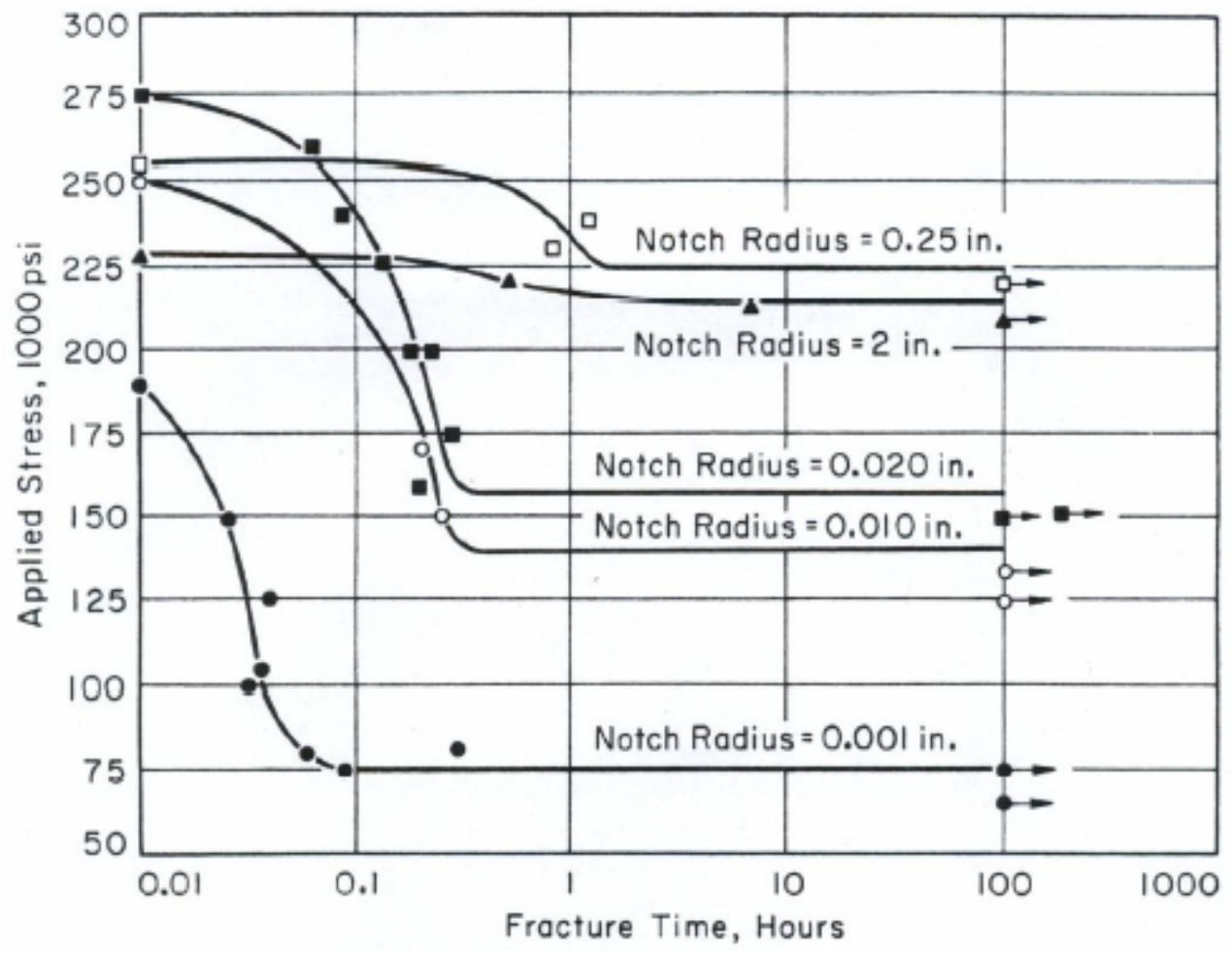

Figure 24. Effect of Notch Root Radius on Delayed Failure Processes in a High Strength Steel. After Figure 3, page 156 of Reference 16 
WSRC-STI-2008-00062

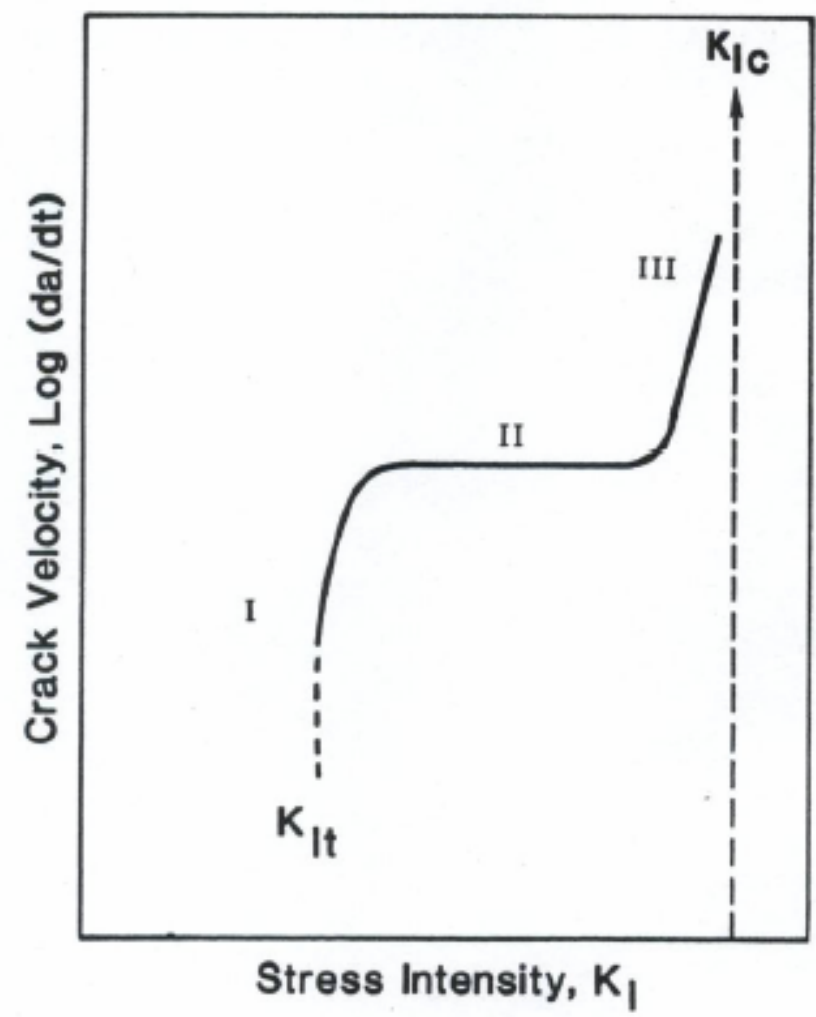

Figure 25. Effect of Applied Stress Intensity on Crack Growth in Hydrogen. After Figure 9, page 14 of Reference 17

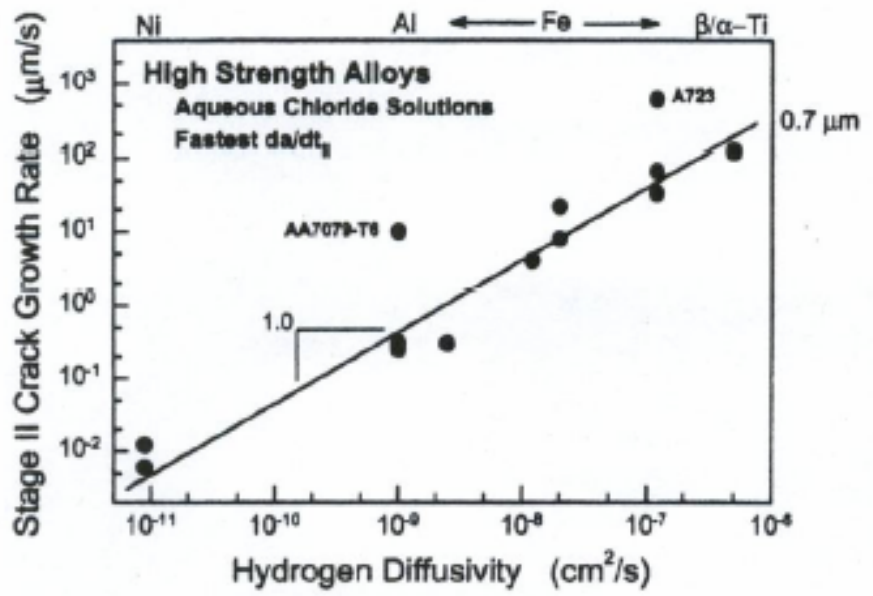

Figure 26. Dependence of Stage II Crack Growth on Hydrogen Diffusivities. After Figure 1, page 480 of Reference 18 
WSRC-STI-2008-00062

FATIGUE BEHAVIOR OF HY-80 AND HY-130

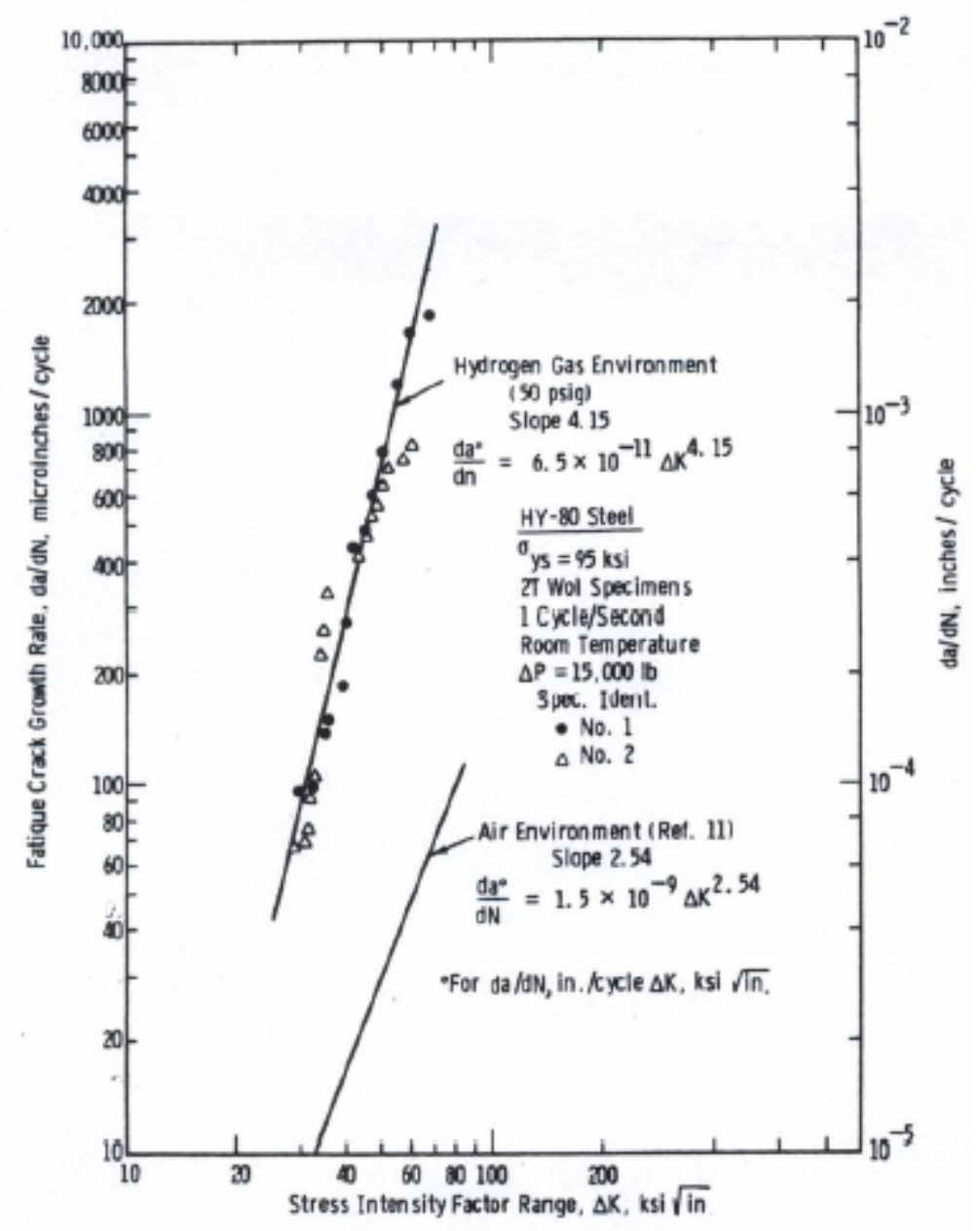

Figure 27. Hydrogen Effects on Fatigue Crack Growth in a HY-80 Steel. After Figure 5, page 157 of Reference 19 
WSRC-STI-2008-00062

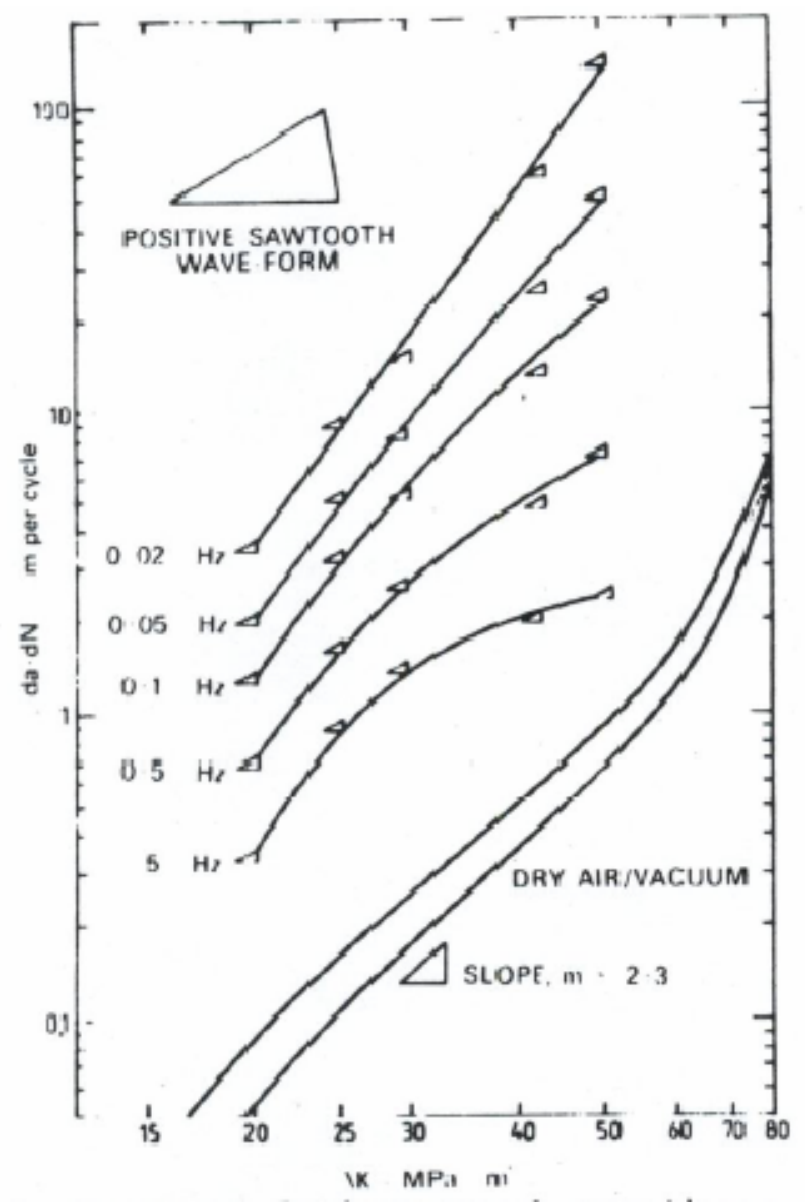

Figure 28. Effect of Cyclic Frequency on Hydrogen Enhanced Fatigue Cracking in a D6aC Steel. After Figure 1, page 376 of Reference 20 


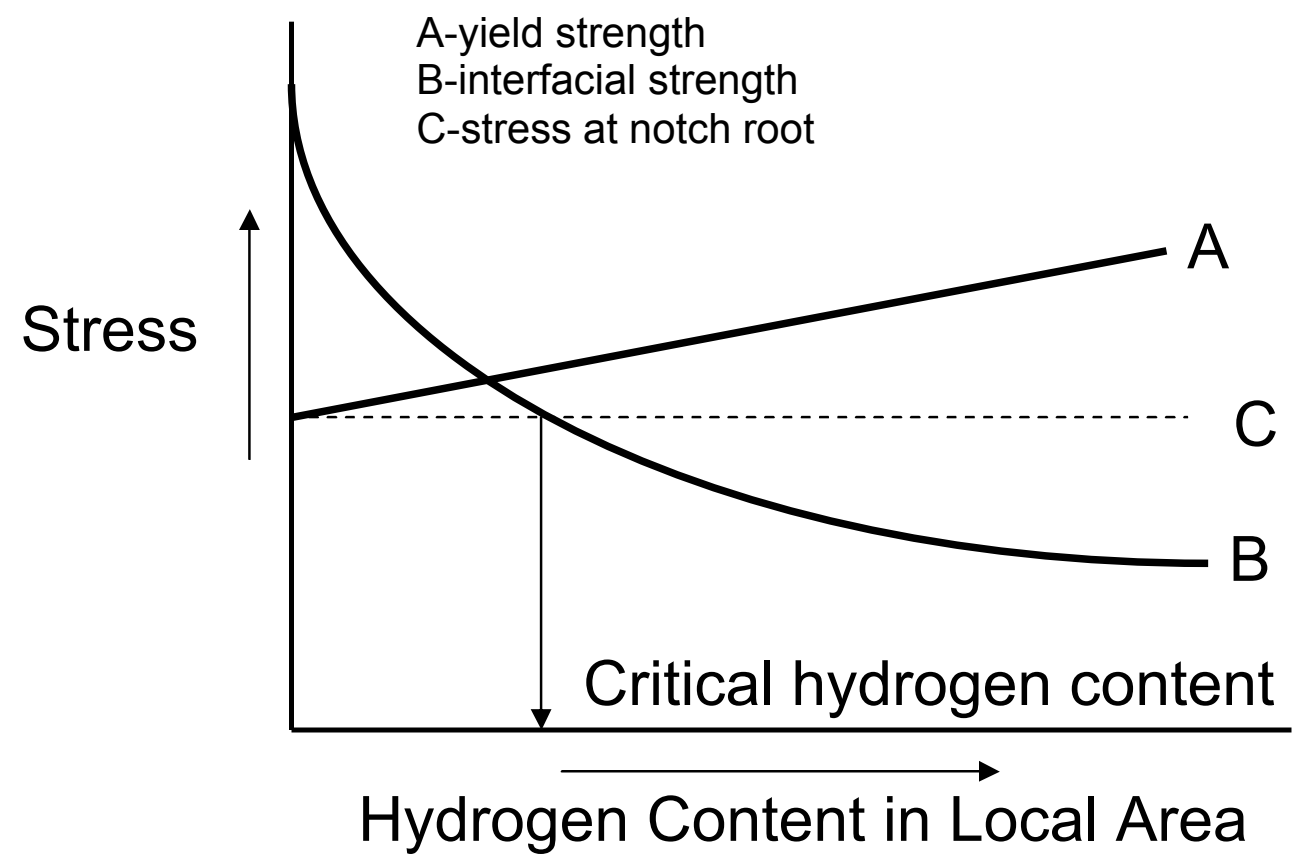

Figure 29. A Description of the Critical Hydrogen Content 